\title{
VOLENTI NON FIT INJURIA? LES EFFETS DU CONSENTEMENT À L'INTERVENTION MILITAIRE
}

\author{
THÉODORE CHRISTAKIS et KARINE BANNELIER
}

\begin{abstract}
"D'accord». L'histoire raconte que c'est par cette réponse laconique que Seyss-Inquart, l'homme de paille imposé par Hitler comme chancelier fédéral d'Autriche, a "consenti ", en mars 1938, à la requête du gouvernement allemand d'envoyer des troupes en Autriche afin d'y " établir la paix et l'ordre » et d' « empêcher toute effusion de sang » 1 . Tout juste deux ans auparavant, c'était aussi au nom de la "préservation de la paix » que vingt-cinq États européens avaient refusé d'apporter leur soutien au gouvernement légitime espagnol dans sa lutte contre les fascistes de Franco en brandissant l'obligation de "s'abstenir rigoureusement de toute ingérence directe ou indirecte dans les affaires de ce pays ", obligation... respectée «scrupuleusement", comme nous le savons, par l'Italie et l'Allemagne. Naguère, la «Sainte alliance » de Metternich invoquait le « respect du droit à l'indépendance de tout pouvoir légitime» pour justifier la défense des monarchies en proie à des mouvements révolutionnaires; par la suite, l'URSS inventera la «défense du socialisme ». Aujourd'hui, c'est la « légitimité démocratique " qui sert d'ornement aux discours interventionnistes de certains. Décidément, les bons arguments ne manquent pas pour plaider tout et son contraire en matière d'intervention sollicitée. Suivant les points de vue de chacun et les intérêts politiques du moment qui les sous-tendent, le droit des peuples à l'autodétermination peut, c'est selon, soit être « servi » soit être « détruit » par une intervention sollicitée. Et tandis que les gouvernements "amis" ont presque toujours le droit de recevoir assistance, le principe de non-intervention doit être scrupuleusement respecté vis-à-vis des autres. La guerre froide a poussé à son paroxysme ces contradictions comme en témoigne l'attitude de l'URSS qui se considérait légalement habilitée à intervenir en Hongrie, en Tchécoslovaquie ou en Afghanistan pour répondre aux prétendus appels des gouvernements de ces pays, mais qui ne voyait dans les interventions sollicitées des pays occidentaux que des "prétextes néocolonialistes pour envahir un territoire et asservir ses habitants".

Dans ce contexte, il ne faut guère s'étonner que la pratique des interventions sollicitées ait pu être qualifiée de "chaotique ${ }^{2}$. Le caractère surabondant et apparemment «chaotique» de cette pratique, ainsi que les questions juridiques fondamentales que soulèvent ces interventions sollicitées, auraient sans doute pu pousser la doctrine à étudier de manière détaillée ce problème et ses différentes
\end{abstract}

(*) Théodore ChRISTAKIS, professeur à la Faculté de droit de l'Université Grenoble II. ble II.

II. p. 193.

Voy. le jugement rendu le $1^{\text {er }}$ octobre 1946 par le Tribunal de Nuremberg in AJIL, vol. 41, 1947,

2. R. KolB, Ius contra bellum : le droit international relatif au maintien de la paix, Bruxelles, Bruylant, 2003, p. 228. 
dimensions. Toutefois, peu d'études d'ampleur lui ont été consacrées ${ }^{3}$. L'objectif de cet article est donc de contribuer à éclairer une question qui, malgré la fin des divisions de la guerre froide, n'a absolument rien perdu de son actualité comme en témoignent les nombreuses interventions sollicitées de ces quinze dernières années.

Cette pratique surabondante n'a pas non plus fait l'objet de sentences arbitrales ou d'arrêts rendus par des juridictions internationales ${ }^{4}$. Ce n'est que dans l'affaire des Activités armées sur le territoire du Congo (RDC c. Ouganda), actuellement en délibéré devant la Cour internationale de justice, que la question du consentement à l'intervention militaire a occupé une part conséquente de l'argumentation des parties au litige. En attendant cet arrêt, force est de constater que, jusqu'à présent, la Cour n'a abordé ce problème que dans un obiter dictum, en conclusion de ses développements sur le principe de non-intervention, dans l'arrêt relatif aux Activités militaires et paramilitaires au Nicaragua, où elle a souligné que :

«On voit mal en effet ce qui resterait du principe de non-intervention en droit international si l'intervention, qui peut déjà être justifiée par la demande d'un gouvernement, devait aussi être admise à la demande de l'opposition à celui-ci ». ${ }^{5}$

Si la conclusion de la Cour selon laquelle l'intervention au profit des rebelles et de l'opposition est toujours prohibée demeure indiscutable comme le confirmera la présente analyse, il reste en revanche à savoir si l'intervention ${ }^{6}$ au profit d'un gouvernement en place peut, quant à elle, être considérée comme toujours «justifiée».

Pour répondre à cette question, il convient tout d'abord de déterminer les principes juridiques pertinents pour évaluer la « licéité » de l’intervention sollicitée. Il s'agit d'un problème méthodologique fondamental car la Commission du droit international ainsi qu'une grande partie de la doctrine ont approché le problème de l'intervention sollicitée sous l'angle des «règles secondaires", relatives à la

3. Les seules monographies consacrées à ce sujet sont, en langue française, la thèse de M. BENNOUNA, Le consentement à l'ingérence militaire dans les conflits internes, Paris, LGDJ, 1974, $234 \mathrm{p}$. et, en langue allemande (avec un résumé en anglais), la thèse de G. NOLTE, Eingreifen auf Einladung, Springer, 1999, 699 p. En langue anglaise nous n'avons pu trouver aucun ouvrage consacré exclusivement à ce sujet, mais on peut citer, parmi les articles les plus intéressants, celui de L. DOSWALD-BECK, " The Legal Validity of Military Intervention by Invitation of the Government ", BYBIL, 1985, pp. 189252 .

4. À l'exception du jugement rendu le $1^{\mathrm{er}}$ octobre 1946 par le Tribunal de Nuremberg (op. cit., supra, note 1, pp. 192-194) qui a conclu que l'Autriche n'avait pas donné son consentement à l'Anschluss de 1938 et que même si elle l'avait donné, elle l'aurait fait sous la contrainte.

5. CIJ Rec $1986, \S 246$, p. 126 . Nous soulignons.

6. Deux précisions terminologiques importantes s'imposent quant à l'emploi du terme « intervention ". Il faut souligner, en premier lieu, que plusieurs auteurs attribuent à ce terme un sens forcement péjoratif (une ingérence "dictatoriale" ou "forcée " dans les affaires d'un autre État) refusant, dès lors, son emploi en cas de consentement de l'État. "S'il s'agit d'un accord réel des parties ", écrit par exemple un auteur, «il ne faut pas parler d'une imposition de volonté [...], il ne faut pas parler d'une intervention au sens juridique du terme" (G. MENCER, "Du principe de non-intervention ", Revue de droit contemporain, 1964 (I), p. 37). Or, dans notre article, nous allons utiliser le terme « intervention " de manière complètement neutre, comme l'a fait d'ailleurs la CIJ dans le passage précité de son arrêt de 1986 où elle a clairement indiqué que les interventions peuvent être tantôt illicites, tantôt "justifiées ». La seconde précision concerne la distinction entre intervention militaire directe (envoi de troupes sur le sol de l'État « consentant " dans le but de participer directement aux opérations en cours) et intervention indirecte (assistance militaire plus ou moins importante sans envoi de troupes). Ce n'est en principe que le premier type d'intervention qui va ici nous intéresser, même si nous n'allons pas nous interdire de nous référer, chaque fois que nécessaire, à l'intervention indirecte ou à des situations intermédiaires (comme c'est le cas, par exemple, quand les troupes envoyées sur le sol d'un État " consentant " participent aux opérations militaires de manière substantielle et efficace mais indirecte).
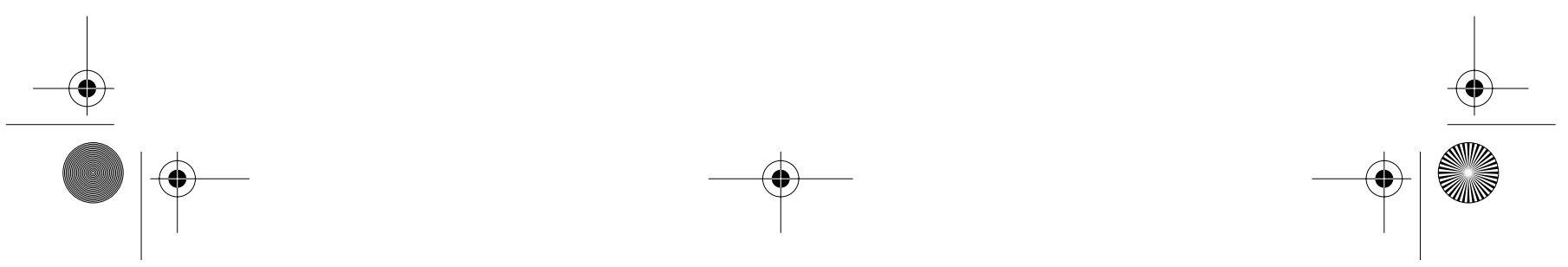
responsabilité internationale. Or, il nous semble que cette approche n'est pas appropriée et que ce sont au contraire les "règles primaires ", et surtout certains principes fondamentaux du droit international contemporain, qui doivent nous guider dans la recherche de la licéité ou non de l'intervention sollicitée. Ce n'est donc qu'après avoir dégagé ces principes pertinents (I), que nous tenterons de les confronter aux diverses situations envisageables afin de proposer une classification des différentes hypothèses d'intervention sollicitée, selon leur conformité ou non avec le droit positif (II).

\section{I. - QUESTIONS MÉTHODOLOGIQUES : LES PRINCIPES PERTINENTS}

Examinons tout d'abord les constructions juridiques qui ont conduit différents auteurs à traiter la question du consentement à l'intervention militaire sous l'angle des "circonstances excluant l'illicéité " et des " règles secondaires " (A), avant de reformuler cette question sous l'angle des « règles primaires » et de rechercher les principes pertinents du droit positif qui pourraient permettre de conclure à la licéité ou à l'illicéité d'une intervention consentie ou sollicitée (B).

\section{A. Le consentement à l'intervention en tant que " circonstance » prévue par les règles secondaires}

La formulation de cette question dans le cadre des règles secondaires " est surtout due aux travaux de Roberto Ago menés au sein de la Commission du droit international. Ces travaux ont abouti à l'introduction d'une "circonstance excluant l'illicéité " dans le chapitre V du projet sur la responsabilité des États intitulée "consentement ", et ont exercé une grande influence sur la doctrine (1). Pourtant, cette approche pose un certain nombre de problèmes et ne permet pas, à notre avis, d'examiner la question de façon satisfaisante (2).

\section{L'approche de Roberto Ago et de la CDI}

Bien des années avant les importants rapports que R. Ago a présentés à la CDI sur la responsabilité internationale, certains auteurs s'étaient déjà demandés si le consentement à l'intervention avait pour effet de rendre cette intervention licite, ou si son effet n'était pas plutôt d'exclure l'illicéité ou, selon une autre variante, d'exclure la responsabilité de l'État intervenant dans ses rapports avec l'État invitant. La première théorie, selon laquelle l'intervention sollicitée serait dès le départ licite, a été développée sous le nom de «théorie de la dénaturation ». Selon celle-ci, le consentement faisait perdre à l'intervention l'un de ses éléments essentiels, la contrainte, et dès lors l'«intervention » ne pouvait plus être qualifiée comme telle car elle était "dénaturée ". "If consent is given freely, there is no imposition of will ", écrivait Thomas en 1956, en ajoutant: "this type of interference cannot be called an intervention ${ }^{7}$. À la théorie de la dénaturation s'est opposée la théorie dite de la légitimation, selon laquelle le consentement de la victime, sans faire perdre à l'intervention sa nature propre, lui faisait seulement perdre son caractère illicite, la légitimait. Comme le

7. Thomas and Thomas, Non-intervention: the Law and its Import in the Americas, Dallas, Southern Methodist U.P., 1956, p. 91.
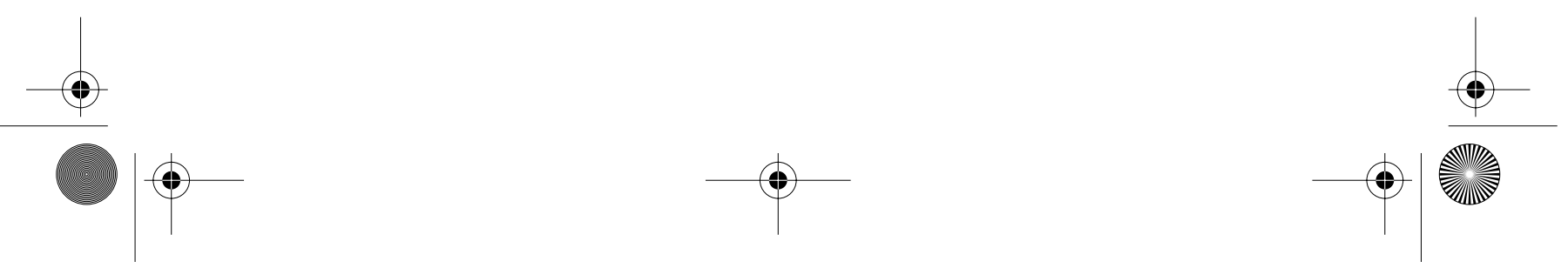
résumait en $1961 \mathrm{~J}$. Charpentier : "le consentement de la victime, dans la théorie de la dénaturation, permet à la puissance intervenante d'écarter in limine litis le reproche d'intervention, de refuser la saisine de toute instance internationale, alors que, dans la théorie de la légitimation, il opère seulement comme une cause d'exonération de la responsabilité dans les rapports entre le responsable et la victime ${ }^{8}$.

Malgré cette première tentative de théorisation, force est de constater que les débats de l'époque tournaient surtout autour de la question sémantique de savoir si le terme "intervention" était approprié ou non en cas d'invitation ${ }^{9}$. Ils ne portaient pas vraiment sur la question de la dichotomie entre règles primaires et règles secondaires et des conséquences qui en découlent. Ce n'est qu'en 1979, avec le Huitième rapport sur la responsabilité des États ${ }^{10}$ du rapporteur spécial de la CDI Roberto Ago, que la question va être formulée dans le cadre de cette problématique. Dans ce rapport, R. Ago soumet en effet à la CDI un certain nombre de propositions pour la codification de ce qu'il appelle (et que l'on a continué à appeler depuis) les "circonstances excluant l'illicéité". Après avoir expliqué pourquoi le terme "circonstances excluant la responsabilité " ne lui semble guère approprié ${ }^{11}$, le rapporteur ouvre le bal des différentes circonstances excluant l'illicéité en commençant par la circonstance qui nous intéresse ici, le consentement ${ }^{12}$.

Dans ses analyses R. Ago explique pourquoi, selon lui, « ne fût-ce qu'en pure logique déjà », le principe volenti non fit injuria s'applique en droit international :

« Si un État [...] consent à ce qu'un autre État adopte un comportement qui, autrement, représenterait la violation d'une obligation internationale à l'égard du premier, ce consentement aboutit manifestement à la formation d'un accord entre les deux sujets, d'un accord faisant que l'obligation internationale cesse d'être opérative entre les deux sujets, ou, du moins, qu'elle est suspendue par rapport au cas d'espèce. L'obligation n'étant donc plus à la charge de l'État, le comportement de ce dernier n'est en contradiction avec aucune obligation internationale, et l'illicéité du fait de l'État est par conséquent exclue " ${ }^{13}$.

R. Ago nous met pourtant en garde contre toute tentative de présenter le comportement en question comme étant « licite » ab initio, et donc sans rapport avec les règles secondaires sur la responsabilité internationale. Selon lui en effet, le comportement en question n'est pas licite, il s'agit plutôt « d'un fait illicite qui devient exceptionnellement licite " ${ }^{14}$, grâce, précisément, au consentement de l'État lésé. Les auteurs qui considèrent qu'il n'existe tout simplement pas de violation du droit international dans une telle hypothèse «ne semblent pas bien se rendre compte du mécanisme même du fonctionnement de celles qu'on appelle les "circonstances excluant l'illicéité" ", soutient ainsi R. Ago. "Le caractère d'exception est précisément

8. J. CHARPENTIER, "Les effets du consentement sur l'intervention », in Mélanges Séfériades, Athènes, 1961 , p. 492

9. Voy. supra note 7.

10. Annuaire de la CDI, 1979, Vol. II, $1^{\text {re }}$ partie, pp. 3 et ss.

11. "Imposer une obligation et laisser en même temps sa violation sans conséquences juridiques équivaudrait en fait à ne pas imposer du tout d'obligation ", souligne ainsi R. Ago. Selon lui en effet, seules deux situations peuvent être envisageables : " ou bien le fait étatique dont il s'agit est qualifié d'illicite, et alors il produit logiquement toutes les conséquences juridiquement prévues pour cette sorte de fait [...], ou bien, en vertu de la présence d'une circonstance déterminée, il est qualifié de licite, et alors il ne produit aucune desdites conséquences " (ibid., p. 30).

12. Circonstance initialement intitulée « consentement de l’État lésé » (id., p. 31).

13. Id., $\S 57$, p. 32 .

14. Id., $\S 67$, p. 36 . Nous soulignons.
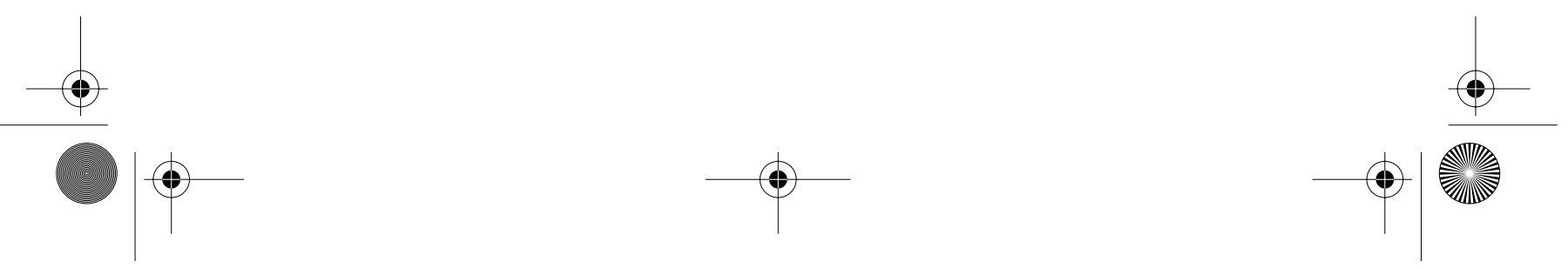
dû au fait que la circonstance dont on constate la présence dans le cas concret rend dans ce cas sans effet une obligation internationale qui, sans cette circonstance, s'imposerait à l'État et rendrait illicite tout comportement non conforme à celui qu'elle requiert. Il y a une différence évidente entre un comportement généralement licite et un comportement généralement illicite et qui resterait tel si une circonstance spéciale ne venait pas, dans un cas concret, enlever ce caractère d'illicéité » ${ }^{15}$.

Pour appuyer cette approche théorique, R. Ago cite la pratique des États qui, selon lui, prouve que « les cas dans lesquels le consentement donné par l'État lésé a été invoqué pour exclure l'existence d'un fait internationalement illicite sont nombreux »16. Dans ce cadre, la pratique relative à "l'envoi de troupes sur le territoire d'un autre État » avec le consentement ou à la demande de ce dernier occupe une place prépondérante. Le rapporteur relève ainsi que « la pratique et la jurisprudence internationales font ressortir que l'entrée de troupes étrangères sur le territoire d'un État est considérée comme une violation grave de la souveraineté de l'État et souvent même comme un acte d'agression, mais il est en même temps évident que cette action perd ce caractère ou devient tout à fait licite si elle a eu lieu à la requête ou avec l'accord de l'État ». Cette conclusion est selon lui confirmée par la pratique, qui va de l'occupation de l'Autriche par les troupes allemandes en 1938, à l'intervention de l'URSS en Hongrie en 1956 ou en Tchécoslovaquie en 1968, en passant par le déploiement de troupes britanniques en Grèce en 1946, au Mascate et Oman en 1957, en Jordanie en 1958, l'intervention des États-Unis au Liban en 1958 ou encore celle de la Belgique en République du Congo en 1960 et 1964. Ainsi, selon Roberto Ago, lors de ces interventions (et d'autres encore), " aucun État ne contesta la validité du principe d'après lequel le consentement de l'État territorial excluait - en thèse générale l'illicéité de l'envoi de troupes étrangères sur son territoire; les divergences portèrent exclusivement sur le point de savoir s'il y avait eu ou non consentement de l'État, si ce consentement avait ou n'avait pas été valablement exprimé, si des droits d'autres États avaient ou non été lésés » 17 .

Ces analyses de R. Ago ont été globalement partagées par la CDI qui a non seulement adopté en 1979, en première lecture (avec quelques modifications mineures), le projet d'article sur le consentement en tant que circonstance excluant l'illicéité ${ }^{18}$, mais qui a aussi, pour le commentaire de cet article, reproduit en grande partie le rapport de R. Ago ${ }^{19}$. Et, en dépit des objections fort judicieuses qu'un autre rapporteur de la CDI sur la responsabilité, James Crawford, formulera à l'encontre de cet article vingt ans plus tard ${ }^{20}$, le consentement en tant que "circonstance excluant l'illicéité » sera finalement maintenu dans le projet d'articles adopté en $2001^{21}$. La doctrine juridique sur les effets du consentement à l'intervention sera d'ailleurs très influencée par les travaux de R. Ago,

15. $I d$

16. Id., §58, p. 32 .

17. Id., $\$ 60$, p. 33 .

18. Sous le titre " consentement ", l'article 29 , § $1^{\mathrm{er}}$ prévoyait en 1979 : « Le consentement valablement donné par un État à la commission par un autre État d'un fait déterminé non conforme à une obligation de ce dernier envers le premier État exclut l'illicéité de ce fait à l'égard dudit État pour autant que le fait reste dans les limites de ce consentement » (ACDI, 1979, Vol. II (Partie II), p. 121).

19. Ibid., pp. 121 et ss.

20. Deuxième rapport sur la responsabilité des États, A/CN.4/498/Add.2 du 30 avril 1999, pp. 10-16.

21. L'article 20 du projet adopté en 2001 prévoit : "Le consentement valide de l’État à la commission par un autre État d'un fait donné exclut l'illicéité de ce fait à l'égard du premier État pour autant que le fait reste dans les limites du consentement" (Rapport de la CDI, 53 e session, A/56/10, 2001, p. 184). Les références à «l'envoi de troupes étrangères dans le territoire d'un État » vont être beaucoup plus laconiques et indirectes qu'en 1979 dans le commentaire succinct qui accompagne cet article ( $c f$. pp. 184-189).
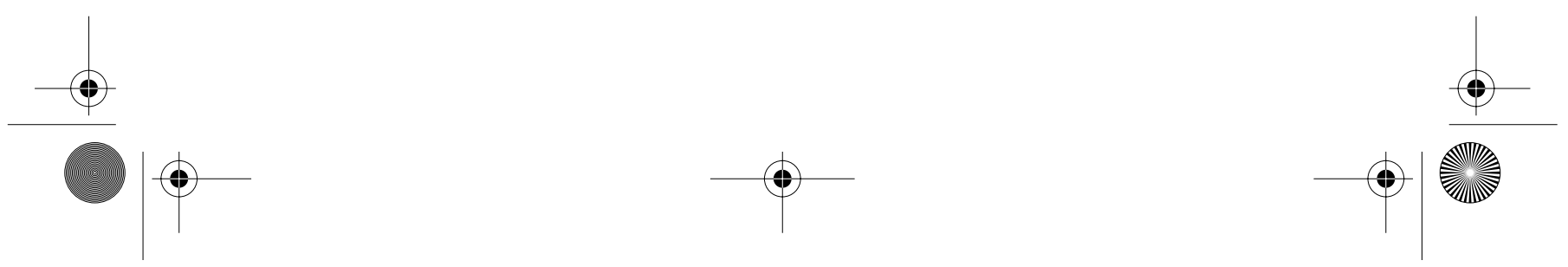
plusieurs auteurs analysant désormais cette question sous l'angle des « circonstances excluant l'illicéité ${ }^{22}$. Cette approche nous semble être pourtant très problématique.

\section{Le caractère problématique de cette approche}

L'examen de la question de l'intervention sollicitée sous l'angle des " circonstances excluant l'illicéité " se heurte à deux difficultés majeures, la première concerne la distinction entre règles primaires et règles secondaires (a) et la seconde concerne la limite imposée par le jus cogens (b).

\section{a) Le problème lié à la distinction entre règles primaires et règles secondaires}

Malgré le grand respect que l'on peut avoir pour les travaux de R. Ago sur la responsabilité, les arguments visant à démontrer que le consentement est une "circonstance excluant l'illicéité " ne sont pas pleinement convaincants. Notre objection ne consiste pas à soutenir, comme l'ont fait certains ${ }^{23}$, que le consentement est une "circonstance excluant la responsabilité ", mais concerne plutôt les effets du consentement sur la qualification initiale d'un fait, soit comme "licite" (auquel cas toute référence aux règles secondaires est inutile) soit, inversement, comme «illicite mais, exceptionnellement, excusable ».

Nous avons vu que, selon R. Ago, le consentement est une «circonstance excluant l'illicéité» dans la mesure où il permet de transformer un acte normalement illicite en un acte licite, de gommer en quelque sorte l'illicéité incontestable d'un comportement. Le mécanisme est donc similaire à celui, bien connu, des représailles. Ceci suppose, néanmoins, l'existence préalable d'une illicéité, car un fait licite n'a guère besoin d'une "circonstance excluant l'illicéité " : si on n'a pas péché, on n'a besoin ni de pardon ni d'indulgences.

Or, ce qui distingue fondamentalement le consentement des autres circonstances prévues par le chapitre $\mathrm{V}$ du projet, c'est que pour les autres circonstances les faits illicites existent déjà au moment où les règles secondaires interviennent, soit pour gommer leur illicéité (si l'on accepte in toto la théorie de l'«exclusion de l'illicite » prônée par la CDI), soit pour exclure la responsabilité de leur auteur (si l'on considère que seul cet effet est possible pour certaines circonstances telles que l'état de nécessité ou la détresse ${ }^{24}$ ). En revanche, l'article 20 qui concerne le consentement joue en quelque sorte de manière «préventive ». R. Ago et la CDI ont beaucoup insisté, et à juste titre, sur le fait que le « consentement » en question doit être donné à l'avance et ils ont de manière très

22. Voy. par exemple : A. TANCA, Foreign Armed Intervention in Internal Conflict, Martinus Nijhoff, 1993, p. 13 : "The best legal approach to the concept of consent in international law is found in the law of international responsibility of States, where is included among the general circumstances precluding the wrongfulness of otherwise unlawful acts commited by States. This general approach can easily be transferred to the more specific problems of armed intervention"; voy. aussi la démarche similaire de N. RonZITTI, Rescuing Nationals abroad through Military Coercion and Intervention on Grounds of Humanity, Martinus Nijhoff, 1985, pp. 77 et ss.; N. RonZITTI, "Use of Force, Jus Cogens and State Consent » in A. CASSESE (ed.), The Current Legal Regulation of the Use of Force, Martinus Nijhoff, 1986, pp. 148 et ss.; O. CORTEN, P. KLEIN, Droit d'ingérence ou obligation de réaction?, Bruylant, Bruxelles,

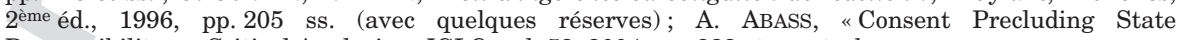
Responsibility : a Critical Analysis ", ICLQ, vol. 53, 2004, pp. 223 et s. ; et al.

23. Voy. V. LowE, « Precluding Wrongfulness or Responsibility : A Plea for Excuses », EJIL, vol. 10, 1999, pp. 405-411.

24. Voy. T. CHRISTAKIS, "Vers une reconnaissance de la notion de guerre préventive ? ", in K. BANNElier, T. Christakis, O. CoRTEN, P. Klein, L'intervention en Irak et le droit international, Paris, Pedone, 2004, pp. 38-41.
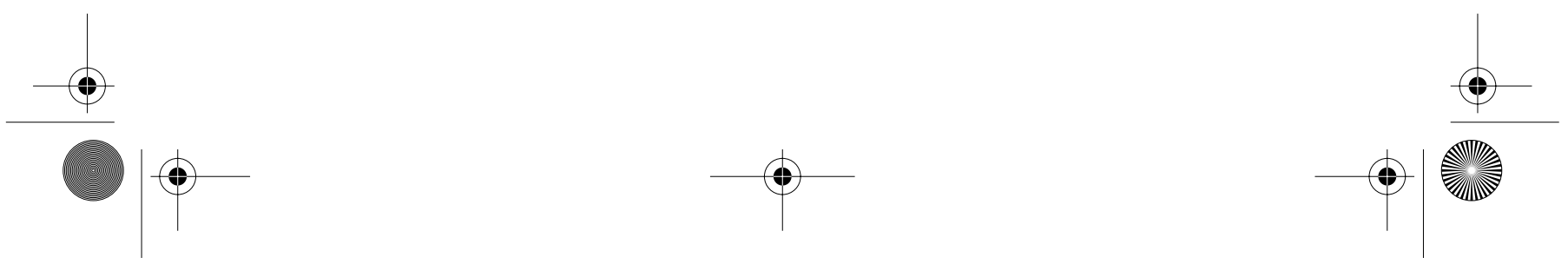
claire distingué cette question de celle de la renonciation, traitée par l'article 45 du projet adopté en $2001^{25}$. Si le consentement est donc donné de manière valable, il est impossible de qualifier le fait d'illicite au moment où il se produit ! L'État qui intervient sur la base du consentement ne viole tout simplement pas le droit international ${ }^{26}$ et l'État qui a lancé une invitation valable n'est certainement pas un État lésé ${ }^{27}$.

Cette absence d'illicéité au moment où le fait intervient a pour curieux effet de nous priver de toute mesure objective nous permettant de qualifier le phénomène qui se produit sous nos yeux. Certains témoins peuvent prétendre qu'ils ont vu une règle secondaire dont l'application a empêché miraculeusement la violation certaine et inévitable d'une règle primaire. D'autres peuvent au contraire jurer qu'aucune règle secondaire n'était présente sur les lieux et qu'aucun crime n'a failli y être commis. Ils peuvent ajouter que le consentement a permis la formation d'un accord de volontés entre deux sujets du droit, et que seules des règles primaires étaient pertinentes en l'espèce, des règles qui intègrent le consentement, permettant à un État de consentir à l'avance à des faits qui, en l'absence de ce consentement (et seulement en l'absence de ce consentement) seraient qualifiés d'illicites.

Sur un plan théorique, on pourrait sans doute accepter ces deux témoignages et la querelle pourrait sembler bien byzantine dans la mesure où le résultat est identique. Ce serait pourtant une erreur que de conclure au caractère oiseux de ces interrogations, car ces deux approches sont animées d'une perception si différente du consentement qu'elles pourraient avoir certaines conséquences pratiques non négligeables.

Si l'on considère en effet que le consentement est une " circonstance excluant l'illicéité ", on accepte l'existence d'une règle secondaire (d'un " principe solidement établi » selon R. Ago ${ }^{28}$ ) valable en toute circonstance. Il est impressionnant, à cet égard, que la CDI n'ait pas cru utile d'accompagner l'article 20 d'une clause de sauvegarde similaire à celle incorporée dans le commentaire de l'article 25 sur l'état de nécessité, selon laquelle "l'état de nécessité n'est pas censé être invoqué à propos de comportements qui sont en principe réglés par les obligations primaires $\gg 29$. Toutes les obligations primaires peuvent donc, en principe, devenir inopérantes par le consentement d'un autre État - la seule limite étant les obligations découlant d'une norme impérative (infra). Mais que se passe-t-il si la règle primaire impose une obligation absolue (mais pas impérative) qui exclut la prise en compte du consentement de l'État à l'égard duquel l'obligation est due ${ }^{30}$ ? Nous allons voir par exemple que le droit international semble interdire l'intervention dans une guerre civile au profit du gouvernement établi. Comment

25. Voy. Rapport de la CDI, 53e session, A/56/10, 2001, pp. 185 et 330 et ss.

26. Comme le souligne l'article 13 du projet, « le fait de l'État ne constitue pas une violation d'une obligation internationale à moins que l'État ne soit lié par ladite obligation au moment où le fait se produit ». Or, dans la logique même de l'article 20, le consentement d'un État a pour effet de rendre inopérante l'obligation et le comportement de l'autre État n'est donc, pour reprendre les mots de R. Ago, « en contradiction avec aucune obligation internationale".

27. R. Ago a dû d'ailleurs abandonner le terme "État lésé » après les réactions de plusieurs membres de la CDI.

28. Huitième rapport sur la responsabilité des États...., op. cit., § 68, p. 36.

29. Rapport de la CDI, A/56/10, 2001, p. 220.

30. La seule échappatoire logique serait de considérer que toute obligation « absolue » est par définition une obligation impérative déjà visée par l'article 26 du projet adopté en 2001 . Ceci conduirait néanmoins à un élargissement considérable de la notion de jus cogens ce qui pourrait, en pratique, avoir des effets « collatéraux » importants.
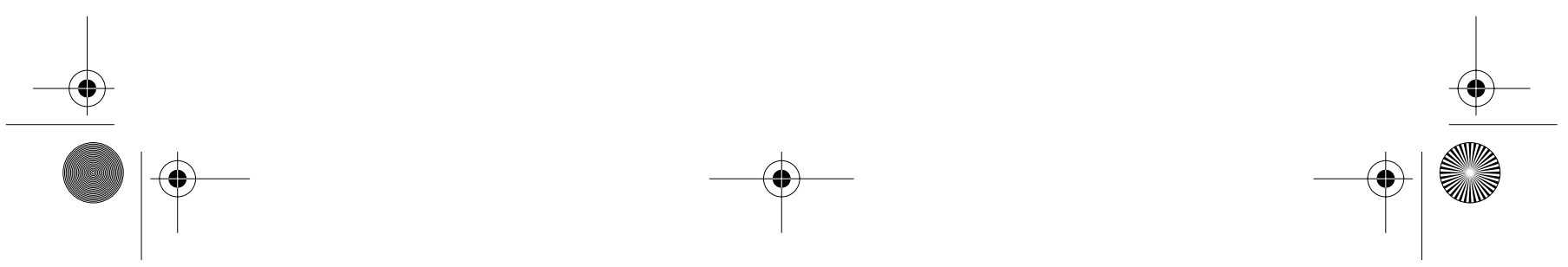
l'article 20 pourrait-il alors rendre licite une telle intervention sollicitée qualifiée pourtant d'illicite par la règle primaire?

L'approche inverse, selon laquelle le consentement n'est, en fin de compte, qu'une question qui intéresse les règles primaires, présente l'avantage d'éviter la formulation d'un quelconque principe général malmené ensuite en pratique. Chaque règle primaire et chaque situation doivent être examinées de manière séparée. Si la règle primaire permet à l'État de consentir à certains faits produits par un autre État, ces faits sont licites dès le départ et il est alors inutile de recourir à une règle secondaire. $\mathrm{Si}$, en revanche, la règle primaire exclut un tel consentement, le fait est illicite, et l'article 20 ne peut nullement venir se substituer à la règle primaire.

Notre objectif n'est pas ici de résoudre de manière définitive cette querelle, mais il nous semble que seule la seconde approche permet d'analyser les effets du consentement à l'intervention militaire. En effet, le problème fondamental de l'analyse de R. Ago (et de la CDI dans son commentaire de 1979) est qu'elle se fonde sur la présomption implicite mais claire que toute intervention sollicitée est en principe illicite (du point de vue des règles primaires) avant de redevenir licite (grâce aux règles secondaires). Quod erat demonstrandum, car en réalité, c'est à l'examen de ces règles primaires qu'il faut procéder pour déterminer si celles-ci interdisent ou non les différents types d'intervention sollicitée.

\section{b) La limite $d u$ jus cogens}

Dans son rapport de 1979, R. Ago reconnaissait l'existence d'une limite importante au "principe de base " selon lequel le consentement constitue une " circonstance excluant l'illicéité " : celle de jus cogens ${ }^{31}$. Sa proposition a non seulement été retenue sans difficulté par la CDI, mais elle a aussi été étendue à l'ensemble des " circonstances excluant l'illicéité ", l'article 26 du projet adopté en 2001 prévoyant que : "Aucune disposition du présent chapitre n'exclut l'illicéité de tout fait de l'État qui n'est pas conforme à une obligation découlant d'une norme impérative du droit international général $» 32$.

Cette affirmation ne semble a priori guère contestable. Pourtant, si l'on suit la logique de R. Ago et de la CDI selon laquelle toute intervention sollicitée est en principe "illicite" (du point de vue des règles primaires) avant de redevenir "licite" (grâce aux règles secondaires), le facteur jus cogens risque très vite de conduire à une impasse logique. Cette impasse est due au fait que la règle primaire qui est censée être violée par un État qui intervient militairement sur le territoire d'un autre État sans le consentement de ce dernier, c'est l'interdiction du recours à la force qui figure à l'article 2, $\S 4$ de la Charte. Or, cette interdiction est précisément considérée par une très grande majorité d'auteurs et d'États comme une norme impérative. La CDI elle-même, lors de la codification du droit des traités, a estimé que « le droit de la Charte concernant l'interdiction de l'emploi de la force constitue en soi un exemple frappant d'une règle de droit international qui relève du jus

31. Partant de l'évidence, à savoir que l'on ne peut déroger à des règles indérogeables, le rapporteur soulignait que « le consentement donné par l'État titulaire du droit subjectif correspondant à une obligation mise à la charge d'un autre État par une règle impérative du droit international général n'a pas pour effet de rendre licite un fait non conforme à cette obligation commis par cet autre État et de libérer celui-ci de la responsabilité qui en découle "(Huitième rapport sur la responsabilité des États...., op.cit., $\S 75$, p. 39). Cf. aussi $§ 57$, p. 32 .

32. Voy. le commentaire de l'article 26, in Rapport de la CDI, A/56/10, 2001, pp. 221 et ss.

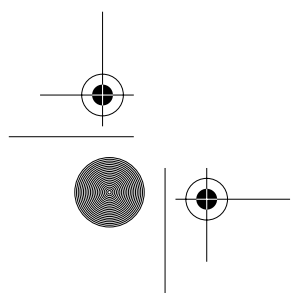


cogens "33. À la lumière de ces remarques, il est donc très difficile de comprendre comment la CDI a pu écrire, dans son commentaire de 1979 sur le consentement que :

«l'entrée de troupes étrangères sur le territoire d'un État [...] est normalement considérée comme une violation grave de la souveraineté de l'État, et souvent même comme un acte d'agression. Mais il est évident que cette action perd ce caractère et devient tout à fait licite si elle a eu lieu à la requête ou avec l'accord de l'État ${ }^{34}$ ».

Comment, en effet, est-il possible qu'un acte d'agression redevienne licite grâce au consentement si, par définition, un État ne peut jamais consentir à une violation du jus cogens, si, en d'autres termes, l'État est incapable de "rendre inopérante " (dans la logique de la CDI) une "obligation découlant d'une norme impérative " ? Pour éviter cette impasse, il n'existe que deux solutions.

La première solution n'est en fait pas vraiment salvatrice. Elle consiste à considérer que ce n'est pas la prohibition du recours à la force qui constitue une norme impérative, mais plutôt la prohibition de l'agression. Cette question avait d'ailleurs été soulevée par R. Ago dans une autre partie de ses rapports qui concernait l'état de nécessité. Le rapporteur se demandait, en effet, si certaines formes de recours très "limité " à la force ${ }^{35}$ pouvaient ne pas constituer une violation du jus cogens (et être éventuellement justifiées par l'argument de l'état de nécessité). Le rapporteur avait d'ailleurs peut-être inspiré la Commission sur ce point car, dans ce qui pourrait être considéré comme une volte-face par rapport à sa position de 1966, celle-ci avait souligné dans son Commentaire sur l'état de nécessité de 1980 qu'il pourrait exister certains «comportements qui, tout en portant atteinte à la souveraineté territoriale d'un État, ne seraient pas nécessairement à considérer comme des actes d'agression ou, de toute façon, comme des violations d'une obligation internationale de jus cogens concernant ce domaine ${ }^{36}$. Mais quel que soit l'intérêt de ce débat sur un plan théorique, voire sur un plan pratique (par rapport à l'état de nécessité ${ }^{37}$ ), il est évident que sa pertinence est relativement limitée pour le problème de l'intervention sollicitée : dans toutes les hypothèses, les "comportements non contraires au jus cogens" envisagés par la CDI ne peuvent concerner que certaines formes de recours très "limité " à la force. Or, dans la majorité écrasante des cas d'intervention sollicitée que la pratique nous offre, il est difficile de ne pas voir, sans l'élément du consentement, une situation similaire à celles décrites par l'article 3 de la résolution 3314 (1974) de l'Assemblée générale de l'ONU sur la définition de l'agression - dont l'alinéa (e) considère d'ailleurs que la simple présence des troupes étrangères sur le sol d'un État après la terminaison d'un accord de stationnement avec le pays d'accueil réunit les conditions d'un acte d'agression. Quoi qu'il en soit, nous avons vu que la CDI n'a guère essayé d'opérer des distinctions aussi subtiles dans son commentaire de 1979 sur le consentement,

33. Commentaire de ce qui est devenu l'article 53 de la convention de Vienne in Annuaire de la CDI, 1966, Vol. II (Partie II), p. 270.

34. Commentaire de ce qui était, en 1979, l'article 29 du projet in Annuaire de la CDI, 1979, Vol. II (Partie II), p. 122. Nous soulignons.

35. Telles que " certaines incursions faites en territoire étranger pour y prévenir l'action préjudiciable d'un groupe armé se préparant à attaquer le territoire de l'autre État » ou « pour éliminer ou neutraliser une source de fléaux menaçant de se produire ou de s'étendre au-delà des frontières " (Additif au huitième rapport..., op. cit., p. $38, \S 56$ ).

36. Annuaire de la CDI, 1980, Vol. II (Partie II), p. 42, § 23.

37. Voy. T. ChRISTAKIS, "Vers une reconnaissance de la notion de guerre préventive?", op. cit., pp. 31-33.
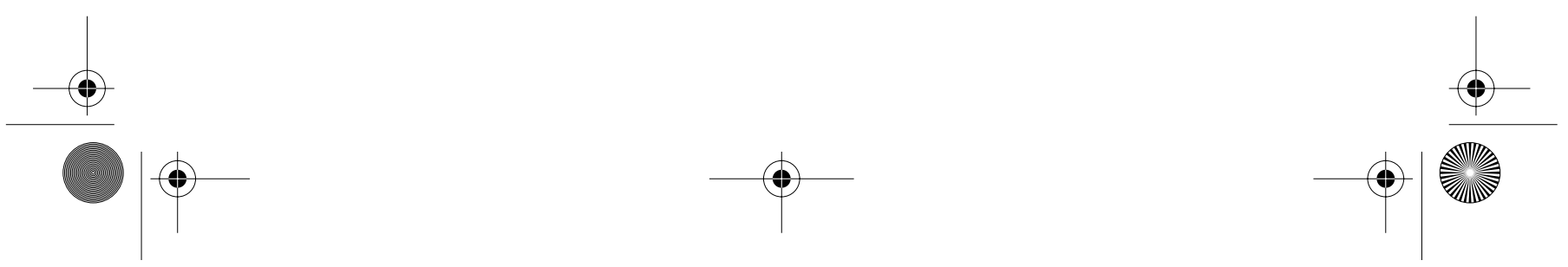
exprimant au contraire l'avis tout à fait extraordinaire que même un acte d'agression "perd ce caractère et devient tout à fait licite si [il] a eu lieu à la requête ou avec l'accord de l'État » ${ }^{38}$

Seule la seconde solution peut donc nous éviter l'impasse. Elle consiste à nous faire sortir du royaume des règles secondaires pour réintégrer celui des règles primaires et ceci afin de montrer qu'une intervention sollicitée précise ne constitue pas en principe une violation de l'article $2, \S 4$ et que la question du jus cogens n'a donc même pas à se poser. C'est ce chemin que finissent inévitablement par emprunter, en connaissance de cause ou non, tous les juristes qui avaient décidé d'examiner la question de l'intervention sollicitée sous l'angle des règles secondaires - qu'il s'agisse de certains membres de la CDI elle-même ${ }^{39}$ ou des auteurs travaillant individuellement sur ce sujet ${ }^{40}$. Ce glissement sémantique constitue une reconnaissance, plus ou moins consciente, du fait que le problème de l'intervention sollicitée n'est pas, en fin de compte, un problème de responsabilité internationale mais plutôt un problème relatif au champ d'application des règles primaires pertinentes, analyse vers laquelle nous allons maintenant nous tourner.

\section{B. Le consentement à l'intervention en tant que situation couverte par les règles primaires}

La première règle primaire pertinente pour apprécier la licéité d'une intervention sollicitée est bien sûr l'interdiction du recours à la force (1), mais elle n'est pas la seule (2).

\section{L'interdiction du recours à la force}

Les règles conventionnelles et coutumières relatives au recours à la force ne font expressément référence qu'à une seule forme d'intervention sollicitée : celle qui concerne la mise en œuvre de la légitime défense collective. Ce mécanisme, qui permet à un État victime d'une agression armée de demander l'assistance de ses pairs, est classique et nullement contesté. Quelles que soient donc les interrogations particulières que sa mise en œuvre peut soulever ${ }^{41}$, il ne va pas, en principe, nous intéresser davantage ici.

38. Op. cit., supra note 35.

39. Voy. par exemple la démonstration de M. Schwebel lors des débats de la CDI sur le consentement en 1979 : " si l'on admet que la règle suprême de jus cogens est la règle énoncée à l'article $2, \S 4$ de la Charte et que cette règle, relevant du jus cogens, ne souffre pas de dérogation, comment l'exemple donné dans le rapport de $\mathrm{M}$. Ago, à savoir celui de la dérogation consensuelle à la règle qui interdit l'entrée de troupes étrangères sur le territoire d'un État, peut-il s'expliquer ? De l'avis de M. Schwebel, la réponse pourrait être la suivante: si des forces étrangères pénètrent sur le territoire d'un État avec le consentement de ce dernier, elles le font pour le maintien, ou tout au moins dans le respect, de l'intégrité territoriale ou de l'indépendance politique de l'État consentant. Ce devrait normalement, sinon toujours, être le cas. Par conséquent, si ce consentement était authentique et autorisé, il n'y aurait pas de difficultés... » (ACDI, 1979, Vol. I, p. 45).

40. Voy. par ex., A. TANCA, Foreign Armed Intervention..., op. cit., p. 47 (admettant que «the consent of the target State would ipso facto bring the action outside the scope of the [peremptory] norm ratione materiae") ou N. RONZITTI, Rescuing Nationals..., op. cit., p. 88 (admettant que «therefore, when a State intervenes in foreign territory with the consent of the local sovereign, it does not violate Article 2 $\S 4 \ldots »)$.

41. Comme, par exemple, la question de savoir si un État tiers peut venir en aide à un État agressé sans la formulation d'une demande expresse de cet État (en cas, par exemple, d'impossibilité matérielle de formulation d'une telle demande par un gouvernement renversé).
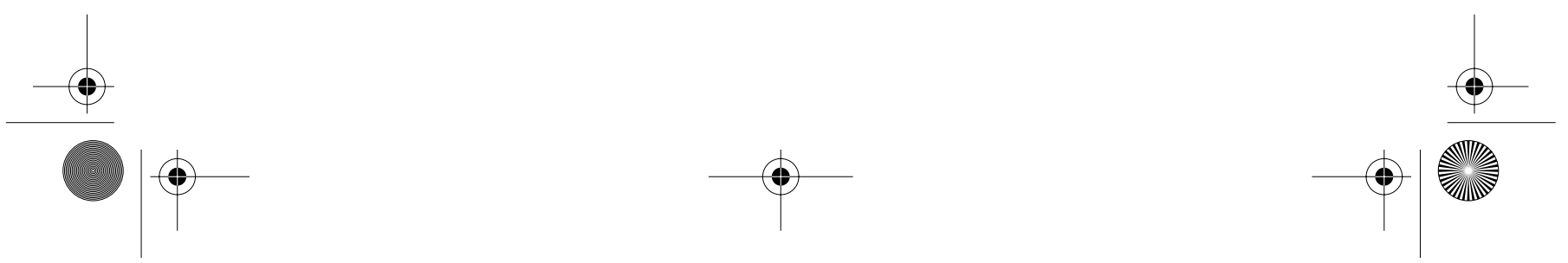
En dehors de cette hypothèse d'une agression armée, les règles relatives au recours à la force ne semblent pas aborder directement le problème de l'intervention sollicitée ou consentie. On peut d'ailleurs remarquer que lorsque les États débattent du jus contra bellum au sein de l'ONU ou dans d'autres fora, ils mentionnent rarement d'autres exceptions que celles prévues expressément par la Charte, à savoir la légitime défense et les mesures coercitives édictées par le Conseil de sécurité. Cela signifie-t-il pour autant une reconnaissance implicite du caractère illicite de l'intervention sollicitée? Rien n'est moins sûr. L'intervention sollicitée n'est certes pas considérée comme une exception à l'article $2, \S 4$ de la Charte, mais elle n'est pas non plus considérée comme en principe contraire à cet article. La véritable question n'est pas donc de savoir si nous avons encore une exception à l'article $2, \S 4$, mais plutôt de savoir si (et à partir de quand) l'intervention sollicitée entre dans le champ d'application ratione materiae de cet article.

Pour répondre à cette question il convient tout d'abord de rappeler que cet article ne prohibe le recours à la force que « dans les relations internationales ». Il est ainsi accepté de façon presque unanime ${ }^{42}$ que la prohibition ne s'applique pas à l'intérieur des frontières d'un État. Un État a donc en principe le droit de recourir à la force pour maintenir l'ordre, mater une insurrection ou combattre un mouvement sécessionniste. Inversement d'ailleurs, le recours à la force d'un mouvement insurrectionnel ou sécessionniste à l'intérieur des frontières d'un État n'est pas non plus prohibé en tant que tel par l'article 2, § 4, étant entendu, bien sûr, que cette force "interne " ne doit pas violer dans tous les cas d'autres règles du droit international (relatives, par exemple aux droits de l'homme, au droit humanitaire, etc.).

La question qui se pose dès lors est de savoir si l'intervention sollicitée d'un État tiers dans une situation strictement « interne " est contraire à l'article $2, \S 4$. Ceci est presque toujours le cas si l'invitation émane d'un groupe d'opposants ou d'une faction interne, car dans ce cas là l'intervention militaire de l'État sollicité se déploie contre l'État qui combat l'insurrection, tel qu'incarné par le gouvernement central. Il s'agit donc bien, dans cette hypothèse, d'un recours à la force «dans les relations internationales". Mais la même conclusion ne s'impose normalement pas si l'invitation émane du gouvernement central effectif de l'État qui sollicite l'aide militaire d'un autre État. Dans une telle hypothèse, il n'est pas possible de parler d'un recours à la force "dans les relations internationales » entre ces deux États puisque ces deux États coopèrent militairement dans le cadre d'une lutte qui reste exclusivement interne du point de vue du jus ad bellum 43 .

Il nous est donc difficile de suivre certains auteurs qui ont pu soutenir que, «si deux États au moins sont impliqués » dans un conflit, il s'agit automatiquement d'un " recours à la force dans les relations internationales " prohibé par l'article $2, \S 444$. En réalité, il s'agit de savoir contre qui est dirigée cette intervention ou, plus exactement, il s'agit de savoir si la force étrangère se déploie contre la volonté et la souveraineté d'un autre État. La résolution 3314 (1974) de l'Assemblée générale de l'ONU sur la définition de l'agression semble bien illustrer, dans son article 3, alinéa (e) déjà cité, l’importance d'une telle volonté

42. Certaines rares tentatives de soutenir le contraire n'ont connu aucun succès. Voy. à cet égard, T. CHRISTAKIS, Le droit à l'autodétermination en dehors des situations de décolonisation, Paris, La Documentation Française, 1999, pp. 253-256. Cf. aussi G. NolTE, Eingreifen auf Einladung, op. cit., p. 632 43. L'éventuelle internationalisation du conflit du point de vue du jus in bello est une question entièrement distincte qui ne doit pas ici prêter à confusion.

44. Voy. M. BenNounA, Le consentement..., op. cit., p. 76.
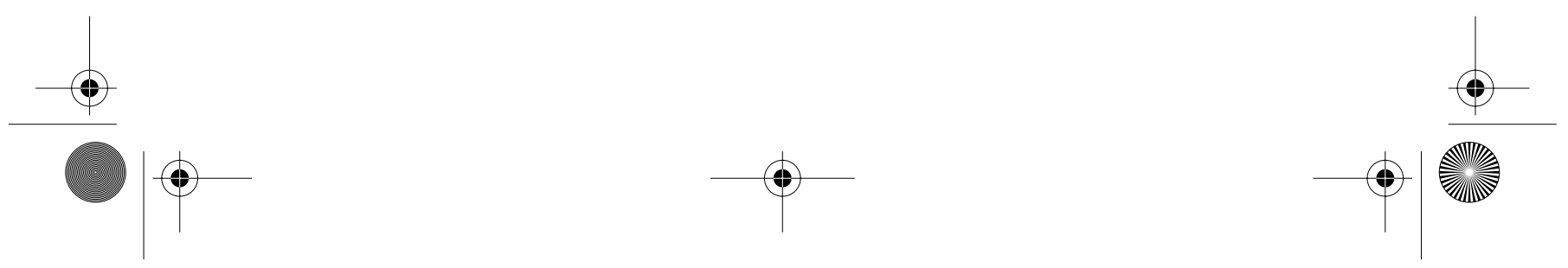
pour la qualification d'une situation aux fins du jus ad bellum. En qualifiant d'agression "l'utilisation des forces armées d'un État qui sont stationnées sur le territoire d'un autre État avec l'accord de l'État d'accueil, contrairement aux conditions prévues dans l'accord", elle admet a contrario la conformité de principe avec les règles du jus contra bellum d'une telle "utilisation ", si celle-ci se réalise conformément à la volonté de l'État d'accueil.

Les «vingt-quatre derniers mots» de l'article $2, \S 4$, parfois avancés pour mettre en cause la conclusion précédente, en soutenant que toute intervention extérieure porte inévitablement atteinte à «l'indépendance politique » de l'État qui invite ${ }^{45}$, ne sont pas non plus capables d'établir une telle présomption générale ${ }^{46}$. Certes, une intervention sollicitée par un gouvernement peut, dans certains cas, se retourner contre la souveraineté de l'État sollicitant et être contraire à l'article $2, \S 4$ de la Charte, et c'est ce que nous constaterons dans la suite de notre analyse (infra, II, C). Mais pour l'instant, il nous suffit de souligner qu'il n'existe aucune présomption de contrariété entre une intervention valablement sollicitée par un gouvernement central et la règle de l'article $2, \S 4$. $\mathrm{Au}$ contraire, une telle intervention semble a priori ne pas entrer dans le champ d'application de cet article. Il est donc nécessaire d'examiner les différentes hypothèses d'intervention sollicitée afin de nous prononcer sur leur éventuelle contrariété avec cet article.

\section{Les autres règles}

Les analyses qui précédent sur «l'indépendance politique » nous conduisent vers les deux autres principes pertinents pour notre sujet, à savoir le principe de non-intervention dans les affaires intérieures (a) et le droit des peuples à disposer d'eux-mêmes (b).

\section{a) Le principe de non-intervention dans les affaires intérieures}

Le principe de non-intervention va au-delà du principe du non-recours à la force, dans la mesure où il constitue une « interdiction faite à tout État, comme corollaire du principe d'égalité souveraine, de s'immiscer dans les affaires internes ou externes relevant de la compétence exclusive d'un autre État ${ }^{47}$. Dans son arrêt du 27 juin 1986 relatif aux Activités militaires et paramilitaires au Nicaragua, la CIJ a souligné le caractère coutumier du principe tout en expliquant que celui-ci «met en jeu le droit de tout État souverain de conduire

45. Il est intéressant de remarquer comment ces "vingt-quatre derniers mots ", habituellement invoqués par certains afin d'affaiblir la prohibition proclamée par l'article $2, \S 4$ (en soutenant en vain que seule l'utilisation de la force ayant une certaine finalité serait interdite), sont ici pour une fois invoqués afin de renforcer cette interdiction!

46. Au contraire même, on pourrait soutenir que l'intervention sollicitée peut aider, dans un certain nombre de cas, l'État qui lance l'invitation à assurer son indépendance politique - surtout si les rebelles trouvent d'une façon quelconque des appuis à l'étranger. $C f$. J. FAWCETT, «Intervention in International Law ", RCADI, 1961-11, t. 103, p. 357.

47. J. SALMON (dir.), Dictionnaire de droit international public, Bruxelles, Bruylant/AUF, 2001, p. 746. Bien que les termes soient souvent utilisés dans la pratique de manière interchangeable, il convient ici de se demander s'il existe une différence entre le principe de non-intervention et celui de non-ingérence. La réponse pourrait être que "l’intervention implique la réalisation d'opérations matérielles " en territoire étranger (y compris bien sûr, mais pas exclusivement, des opérations militaires), tandis que l'ingérence «se limite à une interférence dans la sphère d'action de l'État, sans autorisation de celui-ci » qui peut, par exemple, prendre la forme «d'une simple prise de position », mais aussi, « à un degré supérieur, celle d'une invitation à agir dans un sens déterminé, éventuellement assortie d'une pression destinée à contraindre le destinataire à le faire». Voy. J. CoMBACAU, S. SuR, Droit international public, Paris, Montchrestien, 6 ème éd., 2004, p. 260.
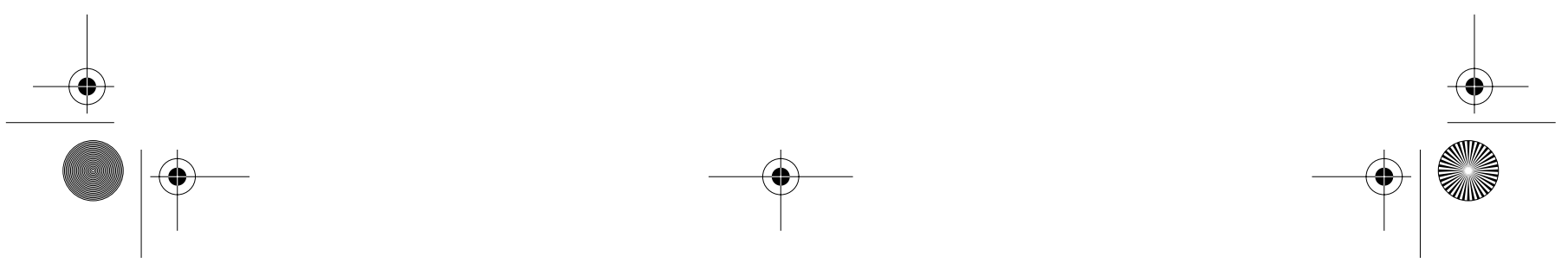
ses affaires sans ingérence extérieure " ${ }^{48}$. Deux séries de remarques s'imposent en relation avec notre sujet.

(i) Analyse théorique - Les auteurs qui cherchent à démontrer l'existence d'une interdiction de l'intervention sollicitée sur la base du principe de nonintervention dans les affaires intérieures, butent immédiatement sur une difficulté logique majeure. Compte tenu du fait que l'État, être corporatif par excellence, est censé être représenté par son gouvernement, comment est-il possible de considérer comme contraire à la volonté de cet État quelque chose qui est voulue par son gouvernement? Comment est-il possible de qualifier d'« intervention prohibée dans les affaires internes » d'un État, une opération qui se déroule à la demande de celui-ci ? S'il y a invitation, il n'y a tout simplement pas d' «intervention" (conçue dans son sens négatif) car il n'existe alors aucune imposition unilatérale de volonté mais plutôt une coopération librement consentie.

Pour sortir de l'impasse, ces auteurs suivent donc la seule voie à leur disposition : ils effacent du débat la notion de gouvernement pour concevoir l'État comme une entité abstraite, dont la sphère interne doit être respectée en toute circonstance. Comme l'écrit Louise Doswald-Beck :

"The duty not to intervene in the civil strife of another State can only be rationa-

lized by perceiving the recipient of the duty as the State in abstracto. The persona-

lity of the State as such thus holds the right and for the purpose of this norm the government does not exclusively represent the State 49.

Le problème que pose néanmoins cette approche est que, si elle permet d'apporter une solution commode au problème de l'intervention sollicitée, elle condamne en même temps l'État à un isolement juridique complet car celui-ci, faute d'organe représentatif, est incapable de s'engager internationalement en limitant son domaine de compétence exclusive. Or, on sait très bien que ce n'est pas ainsi que les choses se passent dans l'ordre juridique international. Les juridictions internationales ont eu l'occasion, à maintes reprises, de souligner que les États peuvent, par le biais de leur gouvernement, limiter leur domaine réservé ${ }^{50}$ et que cette capacité d'autolimitation constitue un attribut essentiel de leur souveraineté ${ }^{51}$. D'ailleurs, dans l'hypothèse précise d'une intervention sollicitée qui nous intéresse ici, l'État qui lance l'invitation ne « s'engage » point envers l'Etat intervenant. Il cherche seulement à obtenir une assistance matérielle pour affronter une difficulté interne. Qui peut le plus peut donc le moins : si «l'autolimitation» est en principe permise par le droit international, l'invitation non constitutive d'autolimitation l'est a fortiori.

Il devient donc évident que l'on ne peut pas effacer aussi facilement le gouvernement de l'équation du principe de non-intervention dans les affaires internes. Certes, des questions peuvent parfois se poser quant à l'existence et à l'effectivité d'un gouvernement ou à la validité d'une invitation (infra). Mais le

48. CIJ Rec 1986, § 202, p. 106.

49. L. DoswALD-BECK, "The Legal Validity... », op. cit., p. 243.

50. Dans son avis consultatif du 9 février 1923 concernant les Décrets de nationalité promulgués en Tunisie et au Maroc, la CPJI a souligné que le domaine de "compétence exclusive " concerne des matières pour lesquelles « chaque État est seul maître de ses décisions ». Et elle a ajouté : "La question de savoir si une certaine matière rentre ou ne rentre pas dans le domaine exclusif d'un État est une question essentiellement relative : elle dépend du développement des rapports internationaux. [...] Il se peut très bien que, dans une matière qui, comme celle de la nationalité, n'est pas, en principe, réglée par le droit international, la liberté de l'État de disposer à son gré soit néanmoins restreinte par des engagements qu'il aurait pris envers d'autres États " (CPJI, Série $B-n^{\circ} 4$, pp. 23-24).

51. Selon la phrase célèbre de la CPJI dans son tout premier arrêt rendu le 17 août 1923 dans l'affaire du Vapeur Wimbledon (CPJI, Série A - $n^{\circ} 1$, p. 25).
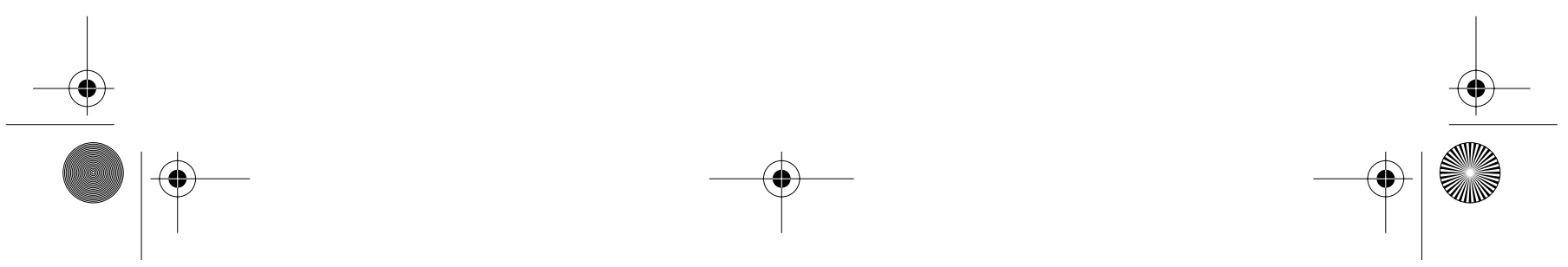
principe est que le gouvernement établi représente l'État dans les relations internationales, qu'il est généralement, comme le souligne un dictionnaire autorisé, "synonyme de l'État qu'il représente » 52 et peut donc adopter diverses décisions concernant la gestion de ses affaires internes.

Le principe de non-intervention dans les affaires intérieures ne devrait donc en principe être considéré comme violé que si cette intervention se déploie sans le consentement de l'État, que s'il existe une "contrainte » imputable à un autre État. C'est exactement dans cette logique que s'est inscrite la CIJ dans son arrêt de 1986 précité, quand elle s'est employée à « définir les éléments constitutifs de ce principe $» 53$.

(ii) Vérification pratique - L'absence de prohibition générale de l'intervention sollicitée par un gouvernement souverain est confirmée par le fait que jamais, à notre connaissance, un instrument général sur le principe de non-intervention dans les affaires intérieures n'a formulé de condamnation expresse et générale de l'intervention sollicitée par un gouvernement établi. Les quelques rares tentatives d'introduire de telles clauses dans certains instruments ont d'ailleurs été repoussées ${ }^{54}$. Très souvent, en revanche, ces instruments prohibent expressément toute aide à des activités subversives contre le gouvernement établi d'un État, laissant penser que seul ce type d'intervention, sollicitée par une fraction interne autre que le gouvernement en place, est interdit.

Ainsi, pour nous limiter aux seuls instruments adoptés au sein de l'Organisation des Nations Unies, on peut remarquer que cette conclusion ressort de façon assez évidente de la première période de la vie de l'Organisation. La résolution $380(\mathrm{~V})$ de l'Assemblée générale du 17 novembre 1950, intitulée « La paix par les actes", condamne toute "intervention d'un État dans les affaires intérieures d'un autre État aux fins d'en changer, en recourant à la menace ou à l'emploi de la force, le gouvernement légalement constitué »55. Cette formulation est d'autant plus significative que la résolution en question a été inspirée par la guerre civile grecque (1944-1949), marquée par les ingérences de plusieurs

52. J. SALMON (dir.), Dictionnaire de droit international public, op. cit., p. 533.

53. Selon la Cour, "ce principe interdit à tout État ou groupe d'États d'intervenir directement ou indirectement dans les affaires intérieures ou extérieures d'un autre Etat. L'intervention interdite doit donc porter sur des matières à propos desquelles le principe de souveraineté des États permet à chacun d'entre eux de se décider librement. Il en est ainsi du choix du système politique, économique, social et culturel et de la formulation des relations extérieures. L'intervention est illicite lorsque à propos de ces choix, qui doivent demeurer libres, elle utilise des moyens de contrainte. Cet élément de contrainte, constitutif de l'intervention prohibée et formant son essence même, est particulièrement évident dans le cas d'une intervention utilisant la force, soit sous la forme directe d'une action militaire soit sous celle indirecte, du soutien à des activités armées subversives ou terroristes à l'intérieur d'un autre État ", CIJ Rec 1986, § 205, p. 108.

54. On pense, par exemple, à la proposition formulée en 1927 par une sous-commission de l'Organisme de Rio d'introduire dans un projet de convention interaméricaine une clause selon laquelle "l'intervention ne saurait être justifiée ni par l'existence d'un traité l'autorisant, ni en cas de guerre civile par l'invitation ou le consentement exprès du gouvernement contre lequel la révolution est dirigée ". Discutée en commission et au cours de la sixième conférence internationale américaine de 1928 , cette proposition ne fut pas retenue. Voy. J. NoËL, Le principe de non-intervention : théorie et pratique dans les relations inter-américaines, Bruxelles, Bruylant, 1981, p. 148.

55. Nous soulignons. Voy. aussi la A/RES 375 (IV) du 6 décembre 1949 intitulée « Projet de Déclaration sur les droits et devoirs des États » où l'Assemblée «prend acte " du projet adopté par la CDI qui, après avoir affirmé de manière générale dans son article 3 que " [t]out État a le devoir de s'abstenir de toute intervention dans les affaires intérieures ou extérieures d'un autre État ", ajoute immédiatement dans son article 4 que « [t] out État a le devoir de s'abstenir de fomenter la guerre civile sur le territoire d'un autre État, et d'empêcher que des activités ne s'organisent sur son propre territoire en vue de la fomenter».
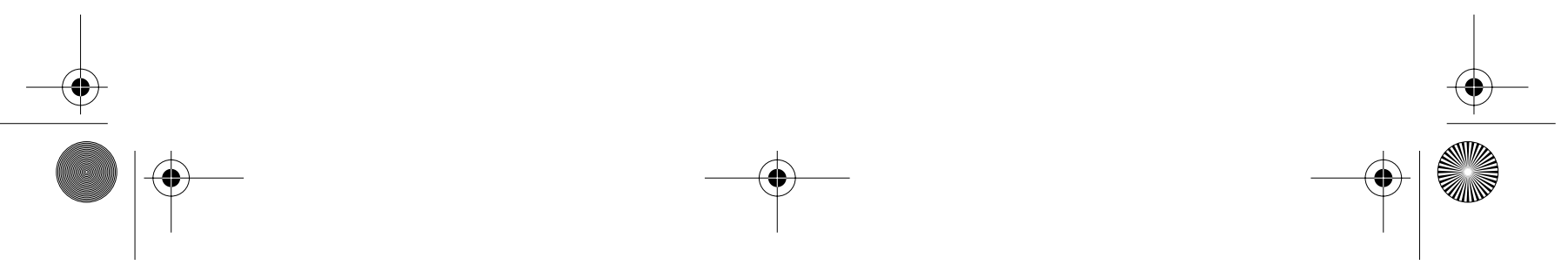
puissances étrangères. Or, bien que le gouvernement grec ait pu bénéficier, à sa demande, d'une assistance militaire importante de la part du Royaume-Uni (dont les troupes ont parfois participé directement aux hostilités) et des États-Unis, l'Assemblée générale n'a jamais considéré cette intervention sollicitée comme illicite, mais a en revanche condamné de manière répétée comme "incompatible avec les buts et les principes de la Charte » l'« assistance et le soutien » apportés par l'Albanie, la Bulgarie et la Yougoslavie à ce que l'Assemblée générale appelait tantôt les "partisans ", tantôt « les franc-tireurs » qui combattent le gouvernement hellénique ${ }^{56}$.

Au cours de la deuxième période de la vie de l'Organisation, très marquée à la fois par la guerre froide et par l'émergence progressive de nouveaux pays issus de la décolonisation, les résolutions consacrées au principe de non-intervention semblent devenir plus générales et s'éloigner de la simple idée d'interdiction d'assistance aux rebelles. Ainsi, la déclaration sur l'inadmissibilité de l'intervention dans les affaires intérieures des États et la protection de leur indépendance et de leur souveraineté, adoptée par l'Assemblée générale le 21 décembre 1965, souligne que :

«Aucun État n'a le droit d'intervenir, directement ou indirectement, pour quelque raison que ce soit, dans les affaires intérieures ou extérieures d'un autre État. En conséquence, non seulement l'intervention armée, mais aussi toute autre forme d'ingérence ou toute menace, dirigées contre la personnalité d'un État ou contre ses éléments politiques, économiques et culturels sont condamnées. [...] Tous les États doivent aussi s'abstenir d'organiser, d'aider, de fomenter, de financer, d'encourager ou de tolérer des activités armées subversives ou terroristes destinées à changer par la violence le régime d'un autre État ainsi que d'intervenir dans les luttes intestines d'un autre État » ${ }^{57}$.

Les expressions employées pourraient donner l'impression que même l'intervention sollicitée par le gouvernement central tombe sous le coup de la prohibition, d'autant plus que cette résolution condamne «la pratique de l'intervention, sous quelque forme que ce soit $" 58$. Toutefois, comme le note un auteur ${ }^{59}$, les travaux préparatoires de cette résolution ne permettent pas de confirmer cette impression. En effet, pratiquement aucun État n'a exprimé lors des débats, l'avis selon lequel toute intervention sollicitée par un gouvernement est contraire au principe protégé par la déclaration ${ }^{60}$. Au contraire même, certains délégués ont souligné qu'un gouvernement a le droit de demander l'assistance militaire des autres États si les éléments dissidents auxquels il doit faire face dans le cadre d'une lutte interne reçoivent " external support and encouragement ${ }^{61}$.

56. Voy. par ex. les résolutions A/RES 109 (II) du 21 octobre 1947 et A/RES 193 (III) du 27 novembre 1948 intitulées "Menaces à l'indépendance politique et à l'intégrité territoriale de la Grèce ".

57. A/RES 2131 (XX), adoptée par 109 voix pour, 0 contre et 1 abstention, $\S \S 1$ et 2 . Nous soulignons.

58. § 4. Nous soulignons.

59. L. DoswALD-BECK, «The Legal Validity... », op. cit., pp. 209.

60. Seuls les représentants de l'Argentine et de l'Italie ont abordé ce problème. Le premier a souligné que "Argentina did not go so far as to deny the right of weak countries to conclude agreements to ensure their security and defense, and in exceptional cases to call on foreign military assistance". Le second a souligné, de manière plus ferme, que "no one had the right to intervene in any way, either for or against movements or governments, according to how he judged them ". Le contexte de cette déclaration du délégué italien ne permet pas, néanmoins, de comprendre s'il s'agit d'une déclaration d'ordre général ou, plutôt, d'une référence aux seules situations de décolonisation et de lutte des mouvements de libération nationale, voire des situations de guerre civile $(i d$.

61. Selon la déclaration du Royaume-Uni, ibid., p. 210.
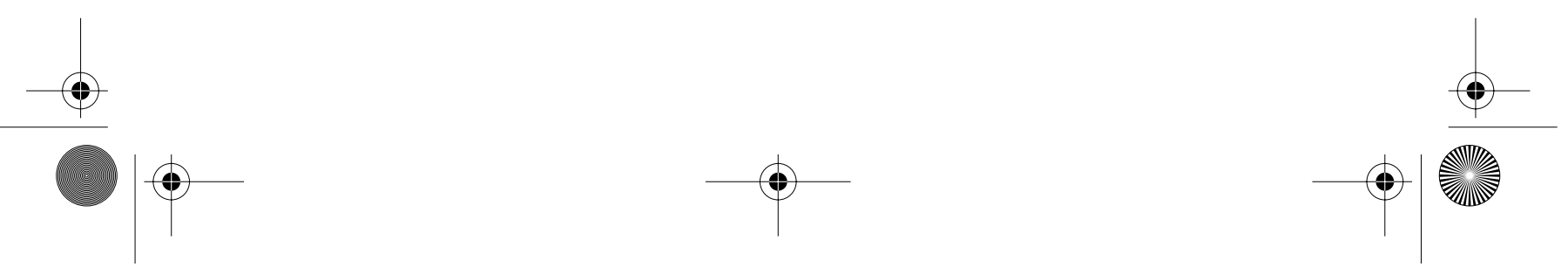
Toujours dans le même contexte politique, il faut bien sûr citer la fameuse déclaration relative aux principes du droit international touchant les relations amicales..., adoptée par l'Assemblée générale le 24 octobre 1970, qui reprend mot pour mot le passage précité de la résolution $2131^{62}$.

Durant une troisième phase de la vie de l'Organisation, marquée par l'achèvement du processus d'accession à l'indépendance d'un grand nombre de pays anciennement colonisés, ainsi que par un relatif apaisement de l'affrontement estouest, les États retrouvent un vocabulaire plus classique dans la formulation du principe de non-intervention. Ceci est visible dans la déclaration sur l'inadmissibilité de l'intervention et de l'ingérence dans les affaires intérieures des États, adoptée par l'Assemblée le 9 décembre 1981, qui, après avoir réitéré de manière générale le principe dans son article premier, s'emploie, dans son article second, à définir avec précision « les droits et devoirs » des États découlant de ce principe. On peut y trouver un grand nombre de références au devoir des États de s'abstenir de tout type d'action destinée à favoriser, encourager ou aider des activités de rébellion ou de sécession contre le gouvernement d'un autre État ${ }^{63}$. Mais on n'y trouve nulle part l'idée selon laquelle l'assistance aux gouvernements établis qui font face à de telles activités est toujours interdite. Tout au contraire, la déclaration souligne de manière assez claire que le principe de non-intervention dans les affaires intérieures concerne :

«Le devoir d'un État de s'abstenir de toute activité économique, politique ou mili-

taire sur le territoire d'un autre État sans son assentiment $» 64$.

Les textes élaborés au sein des Nations Unies sur le principe de nonintervention depuis la fin de la guerre froide ne semblent pas s'inscrire dans une perspective différente ${ }^{65}$. La conclusion qui en découle est donc que le principe de

62. Sous «le principe relatif au devoir de ne pas intervenir dans les affaires relevant de la compétence nationale d'un État ». La résolution 2625 ajoute, d'ailleurs, cette fois-ci dans le cadre du principe du non-recours à la force, le « devoir » de chaque État « de s'abstenir d'organiser et d'encourager des actes de guerre civile ou des actes de terrorisme sur le territoire d'un autre État, d'y aider ou d'y participer, ou de tolérer sur son territoire des activités organisées en vue de perpétrer de tels actes...". Rien n'indique, néanmoins, que cette phrase puisse être interprétée aussi comme une prohibition générale et en toute circonstance de l'assistance militaire à un État en proie à une guerre civile ou à des actes de terrorisme.

63. Voy. par exemple : le devoir « de s'abstenir [...] de recourir à la menace ou à l'emploi de la force sous quelque forme que ce soit pour [...] troubler l'ordre politique [...] d'autres États, pour changer le système politique d'un autre État ou renverser son gouvernement... " (II(a)) ; le devoir « de s'abstenir de recourir à toute intervention armée, subversion, occupation militaire ou toute autre forme d'intervention ou d'ingérence, avouée ou dissimulée, dirigée contre un autre État... » (II(c)) ; le devoir « de s'abstenir de toute action [...] tendant à déstabiliser » un autre État (II(e)) ; ou encore les devoirs proclamés dans les alinéas (f) et (h).

64. Id., al. (o). Nous soulignons. Il convient de souligner que si cette résolution A/RES 36/103 du 9 décembre 1981 a été adoptée par 120 voix pour, 22 contre et 6 abstentions, les abstentions et les votes négatifs ne s'expliquent guère par une opposition au problème qui nous intéresse ici.

65. On peut rappeler ainsi la définition du principe de non-intervention adoptée par la CDI en première lecture en 1991, dans le cadre de son projet de code des crimes contre la paix et la sécurité de l'humanité, selon laquelle « l'intervention dans les affaires intérieures [...] d'un État consiste à fomenter des activités armées subversives ou terroristes, ou à organiser, aider ou financer de telles activités ou à fournir des armes aux fins de telles activités, portant ainsi gravement atteinte au libre exercice par cet État de ses droits souverains» (voy. ACDI, 1995, Vol. II, Partie II, p. 23). On peut aussi mentionner la résolution intitulée «Intervention armée et droit des peuples à l'autodétermination ", adoptée le 12 août 2002 par la sous-commission de la promotion et de la protection des droits de l'homme, qui « se déclare fermement opposée à toutes les interventions militaires étrangères contraires aux principes et autres dispositions de la Charte des Nations Unies ainsi qu'à toutes les menaces de renversement par la force armée de gouvernements dûment constitués, parce qu'elles constituent des violations flagrantes des principes d'autodétermination, d'égalité souveraine et de non-intervention dans les affaires relevant essentiellement de l'ordre juridique interne de tout État..." (Résolution 2002/1, in Rapport de la souscommission, E/CN.4/2003/2, 19 novembre 2002, p. 13. Nous soulignons).
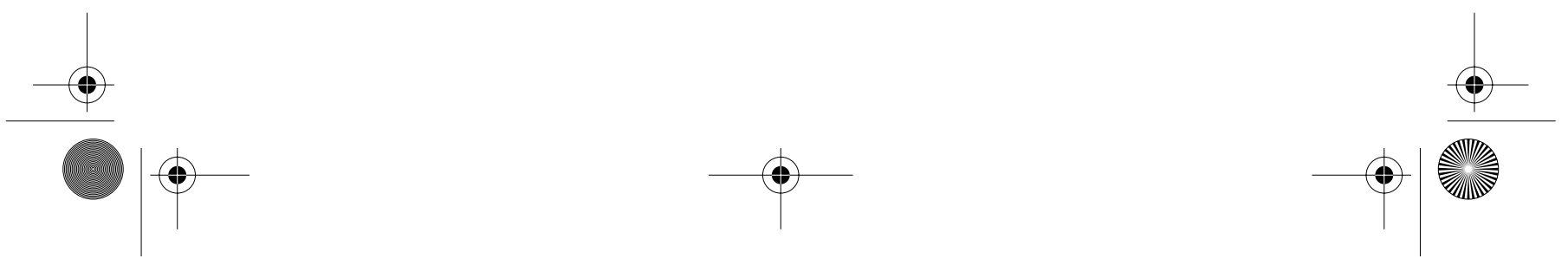
non-intervention, tel qu'interprété par les organes des Nations Unies, ne prohibe pas, en tant que tel, une intervention militaire qui s'effectue sur la base du consentement du gouvernement d'un État.

Cette conclusion semble être d'autant plus valable que le principe de nonintervention s'impose non seulement aux États, mais aussi à l'ONU elle-même. On sait en effet que l'article $2, \S 7$ de la Charte interdit aux Nations Unies d'«intervenir dans les affaires qui relèvent essentiellement de la compétence nationale d'un État", sauf, bien sûr, en cas d'application des mesures de coercition prévues par le chapitre VII. Ainsi, seul le consentement du pays hôte a permis à l'ONU de déployer sur le territoire des États membres les fameuses opérations de maintien de la paix (au moins aussi longtemps que celles-ci ne s'appuyaient pas sur un mandat du chapitre VII). Il convient, à cet égard, de souligner que la tentative de certains auteurs de prouver, d'une façon ou d'une autre, que le consentement du gouvernement établi n'est pas suffisant et que l'ONU aurait aussi besoin du consentement des autres parties à un conflit interne «opposants, mouvement insurrectionnel, province sécessionniste ou communauté ethnique»66, est vaine. Certes, des considérations pratiques évidentes peuvent pousser les forces de l'ONU à chercher (de manière informelle le plus souvent) une certaine coopération de la part des rebelles dans une situation de conflit interne. Mais juridiquement, le consentement d'une entité quelconque autre que le gouvernement établi n'est pas nécessaire. Au contraire même, l'ONU semble considérer que les principes de souveraineté territoriale et de non-intervention dans les affaires intérieures s'opposent à la recherche du consentement des entités non étatiques qui pourrait être perçue comme une reconnaissance de leur effectivité et donc comme une ingérence ${ }^{67}$.

\section{b) Le droit à l'autodétermination}

L'analyse qui précède montre donc que le principe de non-intervention dans les affaires intérieures n'est pas un principe d'isolement complet de l'État, mais plutôt un principe qui vise à protéger, pour citer encore la CPJI, "la liberté de l'État de disposer à son gré " de certaines matières internes, de protéger son pouvoir d'être "seul maître de ses décisions » 68 . Il s'ensuit que l'intervention librement et valablement sollicitée par le gouvernement d'un État est compatible avec ce principe et que la CIJ avait donc bien décrit l'état du droit positif en concluant, dans son arrêt de 1986, que l'intervention « peut [...] être justifiée par la demande d'un gouvernement $» 69$.

Mais si cette intervention peut être justifiée, elle n'est pas nécessairement toujours justifiée. Si la Cour énonce un principe général, il va de soi qu'il peut exister certaines circonstances mettant en cause l'application de ce principe. De

66. M. BENNOUNA, Le consentement..., op. cit., p. 207. Voy. plus généralement ses analyses pp. 198 et 207-210 où il parle de la prétendue "nécessité du consentement de toutes les parties concernées ". Voy. aussi A.L. KARAOSMANOGLOU, Les actions militaires coercitives et non coercitives des Nations Unies, Genève, Droz, 1970, p. 139 qui soutient que «le gouvernement central, même si sa légitimité constitutionnelle est indiscutable, ne peut donner son consentement que pour le territoire qu'il contrôle».

67. Ainsi que l'a souligné le secrétaire général de l'ONU en 1993: "comme dans le cas des autres activités des organismes du système des Nations Unies, le déploiement des forces des Nations Unies et les autres opérations prescrites par le Conseil de sécurité ne sont normalement entrepris qu'avec le consentement des gouvernements hôtes, les autres parties s'engageant selon qu'il convient à assurer leur concours " (S/26358 du 27 août 1993, § 3. Nous soulignons). Pour une analyse de l'ensemble de cette question voy. E. LAGRANGE, Les opérations de maintien de la paix et le Chapitre VII de la Charte des Nations Unies, Paris, Montchrestien, 1999, pp. 28 et ss.

68. Op. cit., supra, note 51 .

69. Op. cit., supra, note 6
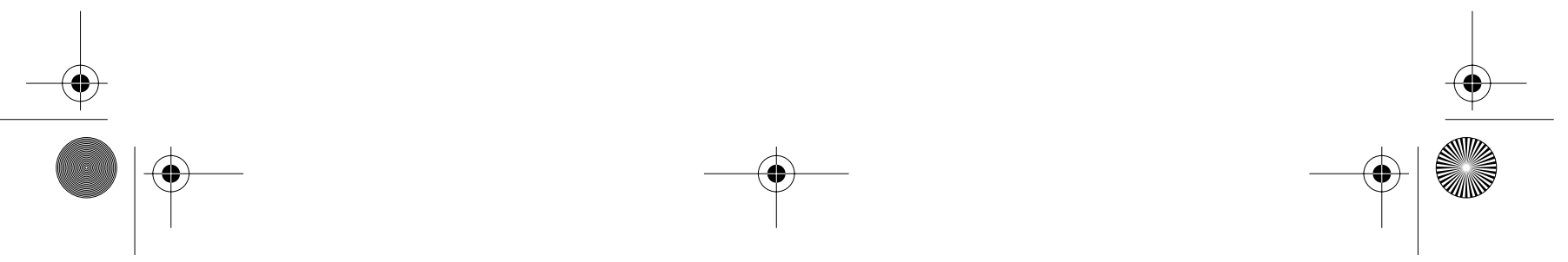
ce point de vue, l'examen du droit des peuples à disposer d'eux-mêmes est particulièrement instructif car il permet de compléter l'analyse qui précède en montrant que certaines finalités précises d'une intervention sollicitée pourraient être contraires au droit positif.

Il est bien connu, en effet, que le droit à l'autodétermination, dans sa conception initiale, a été conçu comme un droit à l'indépendance des peuples colonisés ${ }^{70}$. Très rapidement toutefois, afin de protéger les nouveaux pays contre les tentatives d'ingérence des anciennes métropoles, ce principe a acquis une dimension «interne », conçue comme le droit de l'ensemble de la population d'un État à déterminer librement son statut politique et de choisir librement son régime politique sans ingérence extérieure. Ainsi, l'article premier commun aux deux pactes des Nations Unies de 1966 souligne que «[t]ous les peuples ont le droit de disposer d'eux-mêmes. En vertu de ce droit, ils déterminent librement leur statut politique et assurent librement leur développement économique, social et culturel ", et les travaux préparatoires du pacte montrent bien que cette formule ne vise pas seulement le droit classique d'autodétermination/décolonisation mais aussi l'idée que, une fois décolonisés, les peuples des nouveaux pays «ainsi d'ailleurs que les populations de tous les autres États souverains, devaient être libres de définir leur avenir politique et économique sans ingérences extérieures $» 71$.

Il est important de souligner à cet égard que cette dimension «interne » du droit à l'autodétermination a été consacrée à au moins quatre endroits différents dans la fameuse résolution 2625 de l'Assemblée générale, qui s'éloigne d'ailleurs parfois de la notion de "peuples " pour proclamer un "droit inaliénable » de "tout État [...] de choisir son système politique, économique, social et culturel sans aucune forme d'ingérence de la part d'un autre État " 72 . Ces variations terminologiques ne sont pas dues au hasard. L'utilisation interchangeable du terme «droit des peuples/droit des États » de choisir leur régime politique «sans ingérence externe » montre bien que l'objectif initial de la majorité des États n'était pas vraiment de conférer aux peuples un droit à la démocratie, mais plutôt de créer un rideau de fer juridique, empêchant toute ingérence extérieure dans les choix politiques des nouveaux États. Comme le résume bien un auteur, il était évident :

" that the content of the right to self-determination, that is the right of people to choose its own government, means in effect the absence of outside interference. It does not appear to mean, in the minds of the majority of States, the right to democratic representation or even that the government should reflect the will of the majority of the people. Rather it requires that the government be drawn from a group of people perceived as entitled to self-determination, even if that government actually represents a minority interest within that group and rules by force ${ }^{73}$.

Il ne faut donc pas s'étonner que des régimes autoritaires aient brandi le bouclier du droit à l'autodétermination des États contre les tentatives de certains autres États d'invoquer le... droit à l'autodétermination des peuples pour exiger

70. Voy. T. CHRISTAKIS, Le droit à l'autodétermination..., op. cit., pp. 40-55.

71. Id., p. 336.

72. Formulation que l'on trouve sous le principe de non-intervention (nous soulignons) ainsi que sous celui de "l'égalité souveraine des Etats ». Comp. avec les références au droit à l'autodétermination que l'on trouve sous le principe spécifiquement consacré à ce droit ou encore sous le principe de nonrecours à la force (faisant, ici, référence aux « peuples »).

73. L. DoswALD-BECK, «The Legal Validity... », op. cit., p. 207.
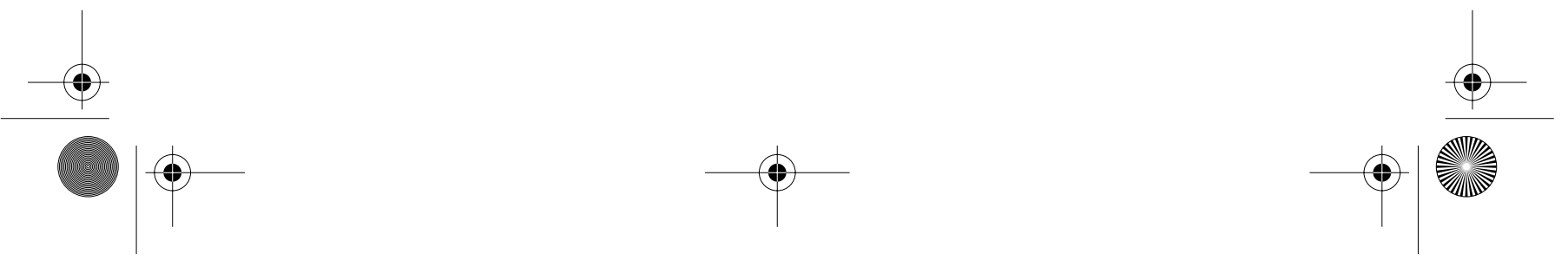
de ces régimes une transition démocratique ${ }^{74}$. Il ne faut pas non plus s'étonner que, comme nous le verrons, lors de débats au sein des Nations Unies suscités par des interventions sollicitées, les chantres du «droit des peuples de choisir librement leur gouvernement sans aucune ingérence extérieure » (sollicitée ou non), constituaient souvent la personnification même du régime totalitaire. Certes, depuis plusieurs années déjà, le droit des peuples à disposer d'eux-mêmes commence à être interprété comme équivalant à un principe de légitimité démocratique ${ }^{75}$ et nous allons voir quelles pourraient être les implications pour notre sujet de l'émergence progressive d'un tel principe. Mais pour l'instant, il nous suffit de remarquer que la règle traditionnelle, élaborée, répétons-le, afin d'éviter qu'une puissance quelconque, de l'Est ou de l'Ouest, puisse «profiter de la faiblesse des États décolonisés pour en tirer des avantages économiques, politiques et culturels ${ }^{76}$, permettait de soutenir avec assez de crédibilité "qu'aucune contestation interne de l'autorité d'un gouvernement ne peut être arbitrée par un État étranger » ${ }^{77}$. Comme l'avait écrit Ch. Chaumont en 1970 :

«Le "droit d'un État de choisir son système" entraîne, dans le droit international contemporain, l'obligation pour les tiers de laisser le peuple de cet État régler luimême les contestations qui s'élèvent en son sein, en ce sens que la position du gouvernement établi n'est juridiquement ni meilleure, ni plus mauvaise, vis-à-vis des tiers, que celle des insurgés $» 78$.

Le droit à l'autodétermination, conçu comme le droit des «tous les peuples de déterminer librement et sans ingérence extérieure leur statut politique " ${ }^{9}$, semble donc compléter le principe de non-intervention précédemment analysé en montrant que certaines interventions sollicitées par le gouvernement établi d'un État pourraient être illicites si leur finalité est de trancher au profit des autorités en place une contestation politique qui vise, précisément, à renverser ces autorités. C'est à la lumière de cette conclusion provisoire qu'il nous est maintenant possible d'établir une typologie des différents types d'intervention sollicitée et d'évaluer leur compatibilité avec les principes que nous venons d'analyser.

\section{II. - APPROCHE PRATIQUE : ESSAI DE CLASSIFICATION}

À la lumière de ce qui précède nous allons maintenant tenter d'établir de manière succincte une classification des interventions sollicitées suivant qu'elles peuvent être considérées comme compatibles ou non avec les principes précités, en mettant l'accent sur la pratique effective des États. Cette pratique et les

74. Les cas sont nombreux. On peut donner l'exemple de l'Iraq de Saddam Hussein qui, réagissant aux critiques sévères formulées contre le régime " totalitaire » et « dictatorial » de Bagdad par le rapporteur spécial de la Commission des droits de l'homme en 1997, a protesté contre ces affirmations qui « devraient être rejetées » car elles "failed to respect the people's right to self-determination and to choose their political system freely ( (voy. T. CHRISTAKIS, Le droit à l'autodétermination..., op. cit., p. 345).

75. Pour une analyse détaillée voy. ibid., pp. 323-506.

76. S. CAlOGeropoulos-Stratis, Le droit des peuples à disposer d'eux-mêmes, Bruxelles, Bruylant, 1973, p. 178

77. J. NOËL, Le principe de non-intervention..., op. cit., p. 143

78. Ch. CHAUMONT, «Cours général de droit international public », RCADI, 1970-I, p. 406

79. Phrase qui continue à être répétée invariablement dans les résolutions que l'Assemblée générale de l'ONU adopte à cet égard. Voy. par ex. la résolution A/RES/54/168 du 25 février 2000 sur le "Respect des principes de souveraineté nationale et de la non-ingérence dans les affaires intérieures des États en ce qui concerne les processus électoraux ", $§ 1$.
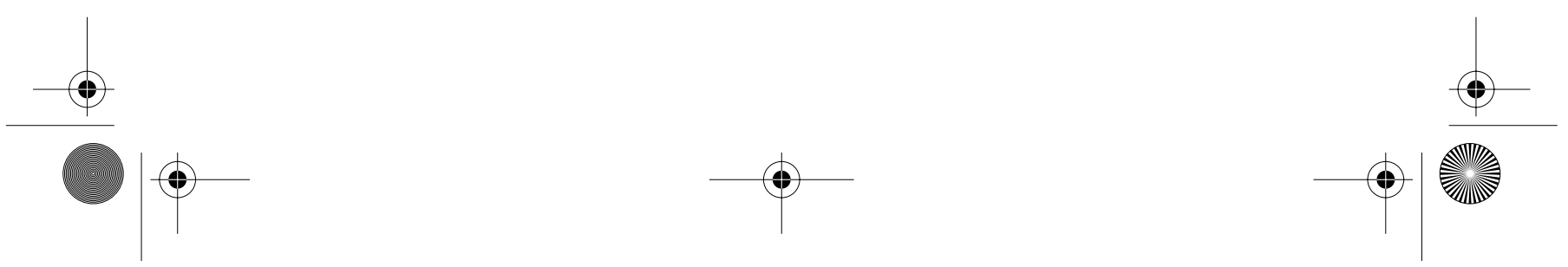
conséquences juridiques que l'on peut en tirer doivent cependant être approchées avec beaucoup de prudence. L'histoire montre en effet que les positions des États ne sont pas toujours guidées par des motivations juridiques. C'est ainsi par exemple que des États ont pu refuser de répondre à une invitation d'intervention sur la base de considérations exclusivement politiques ou économiques. Or, il est clair que ce refus n'est significatif juridiquement que s'il est motivé par la conviction que l'intervention serait contraire au droit. Inversement, l'histoire nous offre aussi des exemples d'interventions prétendument "sollicitées " où néanmoins l'"invitation" était fabriquée de toute pièce. Dans d'autres cas encore, les États impliqués ont essayé de légitimer l'intervention sollicitée sur une base précise (par ex. une agression extérieure) qui était manifestement absente, ou ont invoqué des motifs limités (comme le sauvetage des nationaux à l'étranger) qui étaient en parfaite inadéquation avec l'ampleur de leur intervention. L'examen de la pratique doit donc se faire en parfaite relation avec la recherche de l'opinio juris : il ne faut pas s'arrêter à ce que les États font, mais il faut chercher les justifications juridiques qu'ils avancent à l'appui de ces actions et les réactions que ces justifications et ces interventions soulèvent au sein de la communauté internationale.

Suivant cet appel à la prudence, il est possible de dégager de la pratique trois catégories de situations: celles où l'intervention sollicitée semble conforme au droit positif (A), celles où elle est contraire au droit (C) et une catégorie intermédiaire où l'intervention sollicitée soulève de nombreuses controverses et nécessite un sous-classement beaucoup plus subtil (B).

\section{A. Situations où l'intervention sollicitée semble conforme au droit positif}

Au-delà du mécanisme classique de la légitime défense collective, qui ne va pas, comme nous l'avons expliqué, nous intéresser ici, on peut classer dans cette catégorie trois séries d'hypothèses d'intervention sollicitée qui concernent le sauvetage des nationaux à l'étranger (1), la lutte contre le terrorisme (2) et la lutte contre des rebelles armés qui lancent des attaques transfrontalières (3). Ces trois situations se caractérisent par le fait qu'elles mettent en cause les intérêts d'au moins deux États. La finalité de l'intervention n'est donc pas d'intervenir "dans un conflit interne " mais plutôt de protéger certains intérêts communs.

\section{Consentement à l'intervention pour le sauvetage des nationaux à l'étranger}

La question de l'intervention militaire pour le sauvetage des nationaux à l'étranger est une question classique du droit international et il ne s'agit bien sûr pas de la rouvrir ici. Il suffit, pour les besoins de notre analyse, de souligner que, quels que soient les arguments (et il en existe beaucoup) tendant à démontrer l'illicéité d'une telle intervention unilatérale, il semble exister peu de doutes sur le fait qu'une telle intervention est licite si elle se réalise avec le consentement de l'État sur le sol duquel l'intervention a lieu et si son seul but est bien le sauvetage de ces personnes.

La pratique présente à cet égard deux séries de situations. Dans la première, l'intervention militaire pour le sauvetage des nationaux à l'étranger intervient avec le consentement du pays hôte alors qu'il n'existe pas de guerre civile. Pour ces situations, l'intervention militaire n'a suscité pratiquement aucune réaction négative au sein de la communauté internationale, différents pays exprimant au contraire leur satisfaction à l'égard de ce genre d'opérations. Cela a été par exemple le cas pour un certain nombre d'opérations commando destinées à
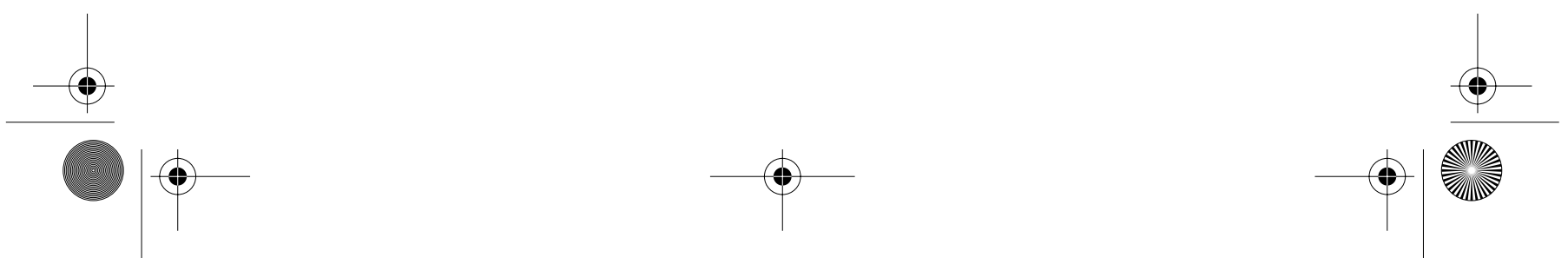
libérer des otages retenus à la suite de détournements d'avions. Dans la mesure où ces interventions se présentent aussi comme des actions antiterroristes, nous les présenterons plus en détail infra.

Dans une deuxième série d'interventions en revanche, l'argument $d u$ consentement au sauvetage des nationaux à l'étranger a été invoqué alors qu'il existait une guerre civile ou au moins une lutte armée pour le pouvoir. Ces interventions ont alors suscité, parfois à juste titre, des réactions des États tiers qui ont considéré que la protection des ressortissants n'était qu'un " prétexte pour intervenir dans les aspects internes du conflit ${ }^{80}$. Notre but ici n'est certainement pas d'examiner la véracité de ce reproche pour chacune des interventions où cet argument a été invoqué. Notre objectif est plutôt de démontrer que les États qui interviennent considèrent qu'ils ont le droit d'intervenir, sur la base du consentement du pays hôte, pour protéger leurs nationaux et que ce droit n'est pratiquement jamais contesté en tant que tel par les États qui dénoncent ces interventions en attribuant aux intervenants des motifs plus obscurs et inavoués. Pour clarifier cette démonstration, nous allons exclure de l'analyse qui suit les interventions militaires où l'argument du sauvetage des nationaux était seulement accessoire par rapport aux justifications principales, celles où la validité du consentement était douteuse et celles qui, très clairement, sont allées au-delà de l'objectif initialement annoncé ${ }^{81}$. Pour ces interventions en effet, les débats et réactions qui les ont accompagnées ont très peu porté sur la question précise qui nous intéresse et il nous semble donc préférable de concentrer notre analyse sur les interventions consenties qui, tout en ayant aussi parfois pu soulever des réactions, ont pour justification principale (ou exclusive), le sauvetage des nationaux à l'étranger.

On peut ainsi tout d'abord citer l'opération conduite par la Belgique et les États-Unis à Stanleyville, au Congo, le 24 novembre 1964, avec le consentement du gouvernement Tshombe. Au moment des faits, Stanleyville se trouvait sous le contrôle de rebelles armés dirigés par $\mathrm{M}$. Gbenye qui, mécontent des positions du gouvernement belge sur la situation au Congo, avait ordonné la détention à leur domicile de tous les "blancs" et avait déclaré qu'il ne pouvait plus garantir la sécurité des sujets belges, menaçant même de les « dévorer "! Devant les organes de l'ONU, le Congo, la Belgique et les États-Unis ont essayé de mettre l'accent sur le caractère exclusivement humanitaire de l'opération ${ }^{82}$. Si plusieurs États

80. Voy. M. BennounA, Le consentement..., op. cit., pp. 172-173 qui cite, par exemple, la déclaration du délégué de l'URSS au Conseil de sécurité en 1964, lors de la crise de Stanleyville, selon qui « l'histoire des conquêtes coloniales a démontré que les colonialistes ont invoqué bien des fois pareils prétextes pour envahir un territoire et asservir ses habitants".

81. Tel semble être surtout le cas des interventions militaires américaines en République Dominicaine en 1965 et à la Grenade en 1983. Christine Gray résume ainsi ces deux interventions : "In both operations [the USA] actually overthrew the old government and installed new governments. Controversy about the existence of the invitation and its constitutional propriety was strong in both cases; in the former the invitation came from unspecified "government officials" and in the latter from the GovernorGeneral, a post without executive powers. The intervention in the Dominican Republic was the first overt military intervention by the USA after the Second World War, designed to prevent the establishment of another communist government in the western hemisphere; its legality was supported in the Security Council only by the UK. There was also criticism in the General Assembly, but no condemnation by other body. The intervention in Grenada was condemned by the UN General Assembly; it said it "deeply body. The intervention in Grenada was condemned by the UN General Assembly; it said it "deeply
deplores the armed intervention in Grenada, which constitutes a flagrant violation of international law and of the independence, sovereignty and territorial integrity of that State" [A/RES 38/7 (108-9-27)] " (C. GRAY, International Law and the Use of Force, Oxford Univ. Press, 2000, p. 64-65).

82. Ainsi, dans une lettre adressée au secrétaire général de l'ONU, le premier ministre congolais avait souligné qu'il avait "autorisé" la Belgique et les États-Unis à apporter à son gouvernement " l'assistance nécessaire à l'organisation d'une mission humanitaire destinée à permettre l'évacuation de ces otages étrangers ", qui étaient, selon lui, « en grave danger ». Lors du débat qui a suivi au sein du
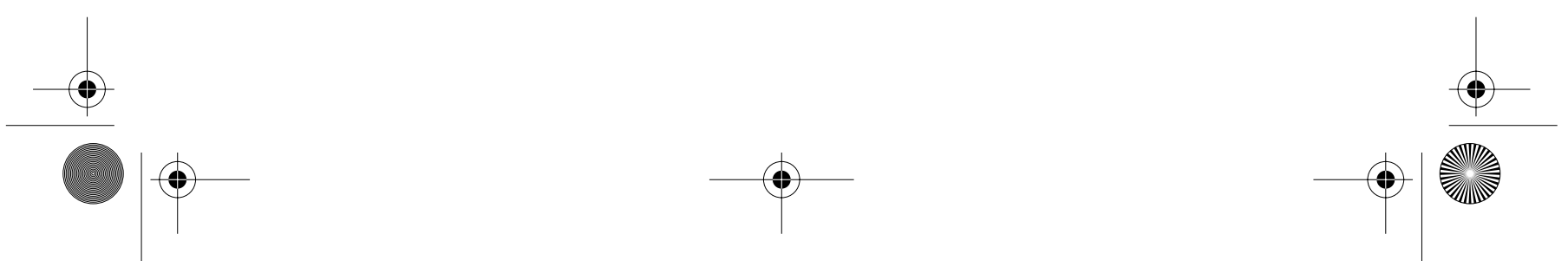
ont alors approuvé celle-ci, reconnaissant parfois expressément le bien fondé d'une intervention humanitaire consentie, d'autres États (des pays africains et l'URSS) l'ont critiquée, en soutenant que son véritable objectif était d'aider le gouvernement Tshombe à reprendre le contrôle des territoires contrôlés par les rebelles et qu'il s'agissait donc d'une « conspiracy to impose upon the people of the Congo the disputed authority of the Tshombe government [...] 83 .

La deuxième intervention qui mérite ici d'être rappelée est l'intervention franco-belge au Shaba en mai $1978^{84}$, justifiée par ces deux pays à la fois par la demande du gouvernement souverain du Zaïre et par la nécessité de protéger leurs ressortissants ${ }^{85}$, même si la France a aussi insisté sur le caractère international du conflit dû à des éléments venant de l'extérieur. Cette intervention n'a pas fait l'objet de débats au sein de l'ONU. Les quelques réactions, formulées surtout au sein de l'OUA, n'ont pas mis en cause le principe même d'une intervention consentie pour le sauvetage des nationaux, mais ont plutôt évoqué l'existence de motifs inavoués 86

Suite de la note 82

Conseil de sécurité la Belgique a souligné que l'opération n'avait « d'autre but que de tenter de sauver les vies humaines en danger " et a ajouté qu'il "ne s'agi[ssait] pas d'une opération ayant un but militaire mais d'une action purement humanitaire dont l'objectif [était] limité au sauvetage de vies en danger ", position partagée par le gouvernement américain qui, dans un communiqué, soulignait que "this opera tion is humanitarian - not military. It is designed to avoid bloodshed - not to engage rebel forces in combat. Its purpose is to accomplish its task quickly and withdraw... ». Voy. A. GERARD, "L'opération Stanleyville-Paulis devant le parlement belge et les Nations Unies ", RBDI, 1967, pp. 242-269 et N. RoNZITTI, Rescuing Nationals Abroad..., op. cit., pp. 78-79.

83. Selon la Tanzanie in S/PV 1178 du 17 décembre 1964. Comme le note un auteur, "[c]ertes, l'opération belgo-américaine [...] a été de courte durée (cinq à six jours) ; il n'en demeure pas moins, étant donné les conditions dans lesquelles elle s'est déroulée, qu'elle a représenté pour l'armée de Tshombe, un appui décisif visant à lui permettre de faire "tomber" la capitale de l'insurrection " (M. BENNOUNA, Le consentement..., op. cit., p. 180). Le Conseil de sécurité a adopté, à l'issu de ces débats, la résolution 199 du 30 décembre 1964 qui «demande à tous les États de s'abstenir ou de cesser d'intervenir dans les affaires intérieures du Congo " (\$1). Toutefois, compte tenu de l'ensemble du contexte du conflit congolais, marqué par les soupçons d'ingérence de plusieurs États et par la présence de mercenaires, il est difficile de lire derrière cette demande générale une condamnation de l'opération américano-belge et le fait que les États-Unis ont voté en faveur de cette résolution confirme cette interprétation.

84. Dans la nuit du 12 mai 1978, un groupe de quatre cents rebelles, conduits par des ex-Katangais venant d'Angola et de Zambie, ont attaqué le Zaïre et ont pris le contrôle de Kolwezi dans la région de Shaba, menaçant la population locale ainsi que la communauté européenne qui y résidait. À la demande du ministre des affaires étrangères du Zaïre, la France, en coopération avec la Belgique, envoya le 19 mai sur Kolwezi des parachutistes qui, dès le lendemain, avaient repris le contrôle de Kolwezi et commençaient l'évacuation des ressortissants européens. Dans les jours qui ont suivi cette évacuation, les troupes belges, puis les troupes françaises se sont retirées de Kolwezi. Voy. A. MANIN, «L'intervention française au Shaba ", AFDI, 1978, pp. 159-188.

85. Le président de la République française déclarait ainsi qu'il s'agissait là d'une "intervention d'humanité à la demande et avec l'accord de l'État intéressé » (cité par L. BALMOND, "Les fondements juridiques des interventions militaires françaises en Afrique" in L. BALMOND, dir., Les interventions militaires françaises en Afrique, Paris, Pedone, 1998, p. 20). Le ministre francais de la défense déclarait à l'Assemblée nationale: "Chacun sait la situation qui règne à Kolwezi et la menace qui pèse sur les Européens. C'est en réponse à la demande du gouvernement légal du Zaïre, que le gouvernement, avec le souci de préserver la vie de nos compatriotes, a par conséquent décidé de prévoir les mesures nécessaires pour garantir leur sécurité » (cité par Ch. ROUSSEAU, "Chronique des faits internationaux ", RGDIP, 1979 , p. 204).

86. Comme en témoigne la déclaration du président de la Tanzanie qui, tout en reconnaissant le droit de chaque gouvernement de demander de l'aide militaire à l'étranger, a estimé qu'un tel droit ne pouvait pas exister lorsqu'il avait pour but « de maintenir au pouvoir un gouvernement corrompu contre la volonté du peuple». Voy. A. TANCA, Foreign Armed Intervention ..., op. cit., p. 171. Voy. aussi N. RoNZITTI, Rescuing Nationals Abroad..., op. cit., p. 83 qui cite un communiqué de l'agence soviétique Tass selon lequel l'opération humanitaire n'était qu'une "fig leaf to cover up an undisguised interference in the internal affairs of Zaire ».

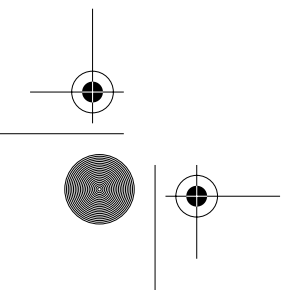


Le sauvetage des nationaux a aussi été officiellement le motif pour l'intervention de la France aux Comores en 1989 qui n'a pas suscité de réactions négatives ${ }^{87}$, pas plus d'ailleurs que l'intervention de la France au Gabon en 1990 (opération Requin), lors de laquelle le ministre français des affaires étrangères insistera de nouveau sur le fait que l'envoi des troupes françaises «ne peu[t] en aucun cas être interprété comme une immixtion dans les affaires intérieures gabonaises [car] ce dispositif a été décidé pour la protection et la sauvegarde de nos compatriotes. [...] Les forces françaises au Gabon ont pour unique mission d'assurer la sécurité des ressortissants français et des opérations de rapatriement volontaire et en aucun cas d'assurer le maintien de l'ordre " ${ }^{88}$. La même conclusion semble pouvoir être tirée de l'examen de certaines interventions consenties plus récentes, comme celles de la France au Zaïre en 1991 (opération Baumier) ${ }^{89}$ et en République centrafricaine en 1996 (opération Almandin $1^{90}$ et opération Almandin 2 ${ }^{91}$ ) ou encore celle du Royaume-Uni en Sierra Leone en $2000^{92}$. Même si, dans certains de ces cas, les États intervenants ont pu donner l'impression d'aller au-delà du motif annoncé (sauvetage des nationaux), ce motif n'a pas fait, en tant que tel, l'objet d'une contestation. S'il est clair que les risques d'abus doivent nous conduire à la prudence et exiger que l'État intervenant prouve que ce motif n'est pas seulement un prétexte pour en réalité intervenir dans une guerre civile, le principe même de la licéité d'une telle intervention consentie ne peut pas être contesté.

\section{Consentement à l'intervention dans le cadre de la lutte contre le terrorisme}

Une intervention sollicitée ou consentie dans le cadre d'une coopération établie pour lutter contre les actes de terrorisme ne semble pas non plus poser de problème

87. À la suite de l'assassinat du président comorien, le mercenaire français Bob Denard s'empare du pouvoir par la force alors qu'il revenait au président de la Cour suprême, Saïd Mohamed Djohar, d'assurer l'intérim. À la demande de ce dernier, la France va alors envoyer un détachement de deux cents parachutistes français, officiellement pour évacuer les ressortissants français de l'archipel. Cette manœuvre militaire et le paiement de sa solde vont pousser Bob Denard à quitter les Comores et permettre à ce pays de restaurer le système démocratique pluraliste qui avait disparu depuis 1982. Poussé par la France, S.M. Djohar va se présenter aux élections présidentielles et devenir ainsi le troisième président des Comores. Pour cette affaire voy. C. POURRE, Les interventions extérieures de l'armée française, Thèse pour le doctorat de droit public, Université Paris Nord, mai 1998, Tome 2, p. 560.

88. L'intervention de la France a suivi la prise en otage du consul de France ainsi que de dix ressortissants français lors de graves émeutes au mois de mai 1990. Plusieurs observateurs ont pourtant reproché à la France d'avoir surtout voulu assurer à Elf Gabon la reprise de ses activités et d'avoir de ce fait permis le maintien en place du régime de M. Bongo (voy. ibid., p. 595 et s.).

89. En septembre 1991, à la suite de violentes émeutes et d'actes de pillages perpétrés par des militaires, la France intervient en coopération avec les autorités de Bruxelles pour procéder à l'évacuation des ressortissants français et européens. Si cette opération pouvait initialement sembler humanitaire, il apparaît aussi qu'elle a permis de sauver le régime Mobutu en accompagnant cette intervention d'une aide financière qui permettra de payer la solde des soldats et de les pousser à rétablir l'ordre dans la capitale (voy. ibid., pp. 594-595)

90. En avril et mai 1996, deux mutineries secouent une partie de l'armée en Centrafrique. La France, appelée à l'aide par son président Ange-Félix Patassé, va intervenir pour garantir la sécurité de ses ressortissants et des étrangers qui le demandent. Cette intervention va aller bien au-delà de la simple protection des ressortissants étrangers. Voy. Le Monde, 22 mai 1996 et infra, note 128.

91. Les soldats français chargés de patrouiller dans les rues de Bangui afin de protéger les biens français vont intervenir en novembre 1996 contre des mutins qui, mécontents de la politique d'AngeFélix Patassé, ont lancé une attaque contre le palais présidentiel. Le président de la République française, Jacques Chirac, va invoquer la protection des ressortissants et déclarer que «les forces françaises ne peuvent participer au maintien de l'ordre " mais « doivent protéger les communautés étrangères » (Le Monde, 6-7 février 1996).

92. Voy. Chr. GRAY, International Law..., op. cit., p. 64 ou « Despite Sierra Leone Plea, Britain to Withdraw Troops in mid-June ", The N.Y. Times, 28 mai 2000.
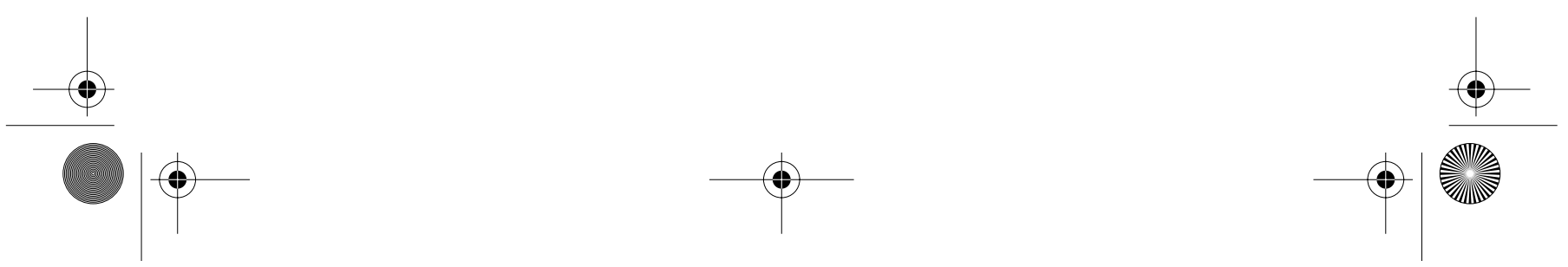
de principe. Certes, ici aussi la prudence s'impose, compte tenu surtout de la difficulté à définir cette notion. Il est en effet évident que deux gouvernements pourraient tenter de qualifier un mouvement insurrectionnel de «terroriste » afin de légitimer une intervention autrement contestable tant sur le plan politique que sur le plan juridique. Sans ouvrir cet immense débat ${ }^{93}$, il suffit ici de remarquer qu'une telle coopération armée pour lutter contre un mouvement terroriste "authentique " ne semble faire l'objet d'aucune contestation sérieuse dans la pratique internationale.

On peut ainsi citer à titre d'exemple l'intervention d'un commando allemand à Mogadishu en octobre 1977 destiné à libérer des otages retenus par des terroristes dans un avion de la Lufthansa. Cette intervention, conduite avec le consentement et la coopération du gouvernement de la Somalie, n'a provoqué aucune réaction négative au sein de la communauté internationale, plusieurs membres ayant même salué son déroulement ${ }^{94}$. Il en va de même avec une opération similaire d'un commando indonésien à Bangkok en mars 1981 qui a permis de libérer les otages d'un avion indonésien détourné par des terroristes islamistes ${ }^{95}$, ou avec l'intervention, pourtant désastreuse, d'un commando égyptien à La Valette en novembre 1985 pour libérer, avec le consentement de Malte, les otages d'un avion détourné d'Egyptair ${ }^{96}$. Ainsi, s'il va de soi que les États n'ont pas l'obligation de consentir à de telles opérations armées antiterroristes sur leur territoire, il est tout aussi clair qu'une décision souveraine de permettre une telle intervention neutralise toute objection quant à la licéité de l'intervention. Il est significatif à cet égard que dans un certain nombre de cas, des États ayant mené de telles opérations à l'étranger ont essayé de les justifier en prétendant que l'État sur le sol duquel se déroulait l'opération avait donné son consentement ${ }^{97}$. Il est tout aussi significatif que des opérations similaires, où le consentement de l'État d'accueil faisait manifestement défaut, ont provoqué de vives réactions de la part de certains États qui ont parfois qualifié ces interventions d'« actes d'agression » 98 .

Au-delà de l'hypothèse d'une intervention consentie destinée à faire face à une situation d'urgence, les États demeurent libres de développer conjointement des opérations militaires afin d'éradiquer des groupes terroristes actifs sur le sol d'un de ces États. S'il est vrai que ces coopérations prennent le plus souvent la forme d'une assistance militaire importante en matériel ${ }^{99}$, voire la mise en place

93. Pour le problème de la définition du terrorisme voy. surtout les contributions de J.M. SOREL, M. Benchikh, M. Kohen et D. Duez in K. Bannelier, T. Christakis, O. Corten, B. Delcourt, Le droit international face au terrorisme, Paris, Pedone, 2002, pp. 35 et ss.

94. Voy. surtout N. RoNZITTI, Rescuing Nationals..., op. cit., p. 79 ; A. TANCA, Foreign Armed Interven tion..., op. cit., p. 47 et A.P. PANZERA, «"Raids" e protezione dei citadini all'estero », RDI, 1978, pp. 762-763.

95. Voy. N. RonZITTI, Rescuing Nationals..., op. cit., pp. 80-81 ou «Indonesia Storm Jet in Bangkok, Freeing All 55 Captives », The N.Y. Times, 31 mars 1981.

96. Voy. "U.S. Backs Raid, Regrets Deaths", The N.Y. Times, 25 nov. 1985.

97. Tel a été le cas, par exemple, lors d'une intervention d'un commando égyptien à Larnaca, en février 1978, destinée à libérer les otages détenus par des terroristes. L’Égypte a invoqué le consentement du gouvernement chypriote mais celui-ci a formellement démenti avoir autorisé les forces égyptiennes à se livrer à des actions militaires sur le territoire de Chypre. Voy. Ch. RousseAU, "Chronique ", RGDIP, 1978, pp. 1096-1097 et N. RONZITTI, Rescuing Nationals..., op. cit., pp. 40-41.

98. Ainsi, lors des discussions au sein du Conseil de sécurité à la suite de l'intervention unilatérale d'un commando israélien à Entebbe, en Ouganda, en juillet 1976, dans l'objectif de libérer les passagers d'un airbus détourné, plusieurs États ont exprimé des vives critiques qualifiant souvent cette opération d'acte d'agression (Voy. S/PV. 1939-1943, 9-14 juillet 1976)

99. On peut citer comme exemple l'assistance militaire demandée par le Yémen aux États-Unis dans le cadre de la lutte antiterroriste. Expliquant que cette demande concerne tant la fourniture d'hélicoptères et d'autres matériels militaires que l'entraînement des troupes yéménites par des militaires américains, l'ambassadeur du Yémen résumait ainsi la demande de son gouvernement aux États-Unis "We're asking for everything: You name it, we want it» (T. RICKS, "U.S. Eyes Military Assistance for Yemen ", The Washington Post, 28 février 2002).
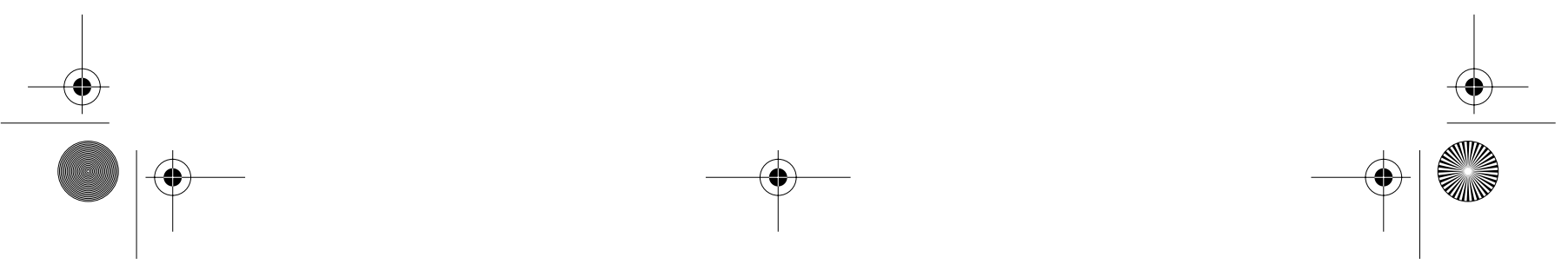
de patrouilles communes aux frontières pour empêcher l'infiltration de terroristes ${ }^{100}$, les États se sont aussi déclarés prêts, dans certains cas, à entreprendre conjointement des opérations militaires de grande envergure pour lutter contre des mouvements terroristes, comme en témoigne, par exemple, le projet concernant le déploiement de trois mille marines américains aux Philippines dans le cadre de la lutte contre le mouvement Abu Sayyaf ${ }^{101}$.

\section{Consentement à l'intervention dans le cadre de la lutte contre des rebelles armés qui lancent des attaques transfrontalières}

Si des rebelles (terroristes ou non) utilisent le territoire d'un État pour s'entraîner, préparer et lancer des attaques subversives contre un État voisin, il est tout à fait concevable que le premier État puisse, dans le cadre de relations de bon voisinage, demander l'assistance armée du second afin de lutter contre ces rebelles. Il est bien connu en effet que les États ne doivent pas seulement s'abstenir de soutenir d'une façon quelconque des groupes qui mènent des actions subversives ou terroristes contre un autre État, mais qu'ils ont aussi l'obligation de ne pas tolérer que de telles actions puissent se développer à partir de leur territoire, ce qui suppose l'adoption de mesures actives de prévention et de répression. L'invitation donnée à l'État voisin de participer à des actions militaires conjointes semble donc être tout à fait conforme au droit international et pourrait difficilement être considérée comme incompatible avec les principes examinés dans la première partie de cet article.

Si la pratique n'est pas très riche dans ce domaine, on peut néanmoins citer l'organisation de patrouilles communes des forces russes et géorgiennes le long de la frontière entre la Géorgie et la Russie, destinée à réduire les activités transfrontalières des rebelles tchétchènes ${ }^{102}$, ou la reconnaissance, dans certains

100. Ainsi, par exemple, le contrôle de la frontière tadjiko-afgane avait été confié depuis 1993 par le Tadjikistan aux forces russes, dans le but de combattre plus efficacement l'infiltration, depuis l'Afghanistan, de terroristes et de réseaux criminels liés au trafic d'hérö̈ne (voy. par ex. A. BoRIssov, « Les Tadjiks remplaceront les Russes à la frontière tadjiko-afghane ", Agence France Presse, $1^{\mathrm{er}}$ octobre 2004 ou, du même journaliste, "Moscou renforce sa présence en Asie centrale ", Agence France Presse, $1^{\mathrm{er}}$ novembre 2004). C'est aussi au nom de la lutte contre les "narcoterroristes " que les États-Unis ont décidé récemment de doubler le nombre de militaires américains présents en Colombie (800 plus 600 « contractuels civils » employés par le Pentagone). Si ces militaires ne participent pas officiellement « directement » aux combats, il n'en demeure pas moins qu'ils sont très actifs (pilotage d'avions et d'hélicoptères, protection de certaines installations, entraînement de troupes, réapprovisionnement de ces troupes en carburant lors des affrontements, utilisation de radars, etc.). Voy. M. DECLAS, «En Colombie, la guerre dure et les États-Unis restent ", Le Monde, 3 nov. 2004 (qui note : "À l'origine, les opérations antiguérilla étaient interdites. Lutte contre le terrorisme oblige, elles ont, depuis, été autorisées par George Bush»); "Colombie : Les États- Unis doublent leur présence militaire », Le Figaro, 16 oct. 2004 ; "Bush's Colombian Connection ", L.A. Times, 23 nov. 2004 et "Plan Colombia - the Sequel ", The Economist, 23 août 2003.

101. Ce projet d'opération militaire conjointe, qui devait constituer une nouvelle étape dans l'assistance militaire importante fournie depuis quelques années par les États-Unis au gouvernement philippin, n'a soulevé, d'après nos informations, aucune protestation internationale. Son exécution a néanmoins était retardée par un arrêt de la Cour suprême des Philippines qui a souligné que, selon la constitution de cet État, des soldats étrangers ne peuvent pas prendre part à des opérations offensives sur le sol philippin et ne peuvent utiliser les armes qu' "en légitime défense ». Voy. B. GRAHAM, "U.S. Military Mission to Philippines on Hold : Conformity with Host's Charter Sought ", The Washington Post, 2 mars 2003. Voy. aussi : "Les rebelles se déclarent prêts à lutter contre les forces américaines ", Xinhua News Agency, 25 déc. 2004 ; "A Fair Fight in the Philippines », The New York Times, 18 octobre 2003 ; "Les soldats américains rempilent pour le bourbier islamiste philippin ", Le Temps, 25 février 2003 ; « Philippines : près de 4000 militaires américains sur le deuxième front de la lutte antiterroriste ", Le Monde, 29 avril 2002.

102. Voy. I. Gedilaghine, "Russes et Géorgiens patrouilleront ensemble à la frontière ", Agence France presse, 6 oct. 2002.
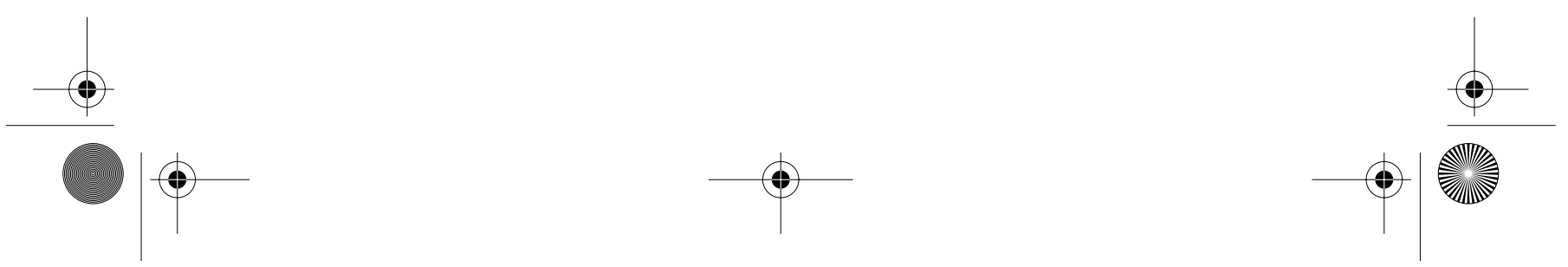
cas, d'un «droit de suite» au profit d'un État voisin ${ }^{103}$. On peut surtout citer l'accueil, par la République démocratique du Congo, de contingents ougandais significatifs entre le mois de mai 1997 et le mois d'août 1998 et la mise en place d'opérations militaires conjointes pour lutter contre les groupes rebelles antiougandais qui utilisaient le sol congolais pour préparer et lancer des attaques contre l'Ouganda. Malgré les nombreux désaccords qui ont opposé ces deux pays lors de la procédure devant la CIJ dans l'affaire des Activités armées sur le territoire du Congo (RDC c. Ouganda), actuellement en délibéré devant la Cour, on peut affirmer qu'aucun des deux pays n'a mis en cause dans son argumentation le principe même de la licéité d'une intervention consentie ${ }^{104}$.

\section{B. Situations où l'intervention sollicitée soulève des controverses}

Les situations que nous allons maintenant examiner concernent des interventions lors de conflits internes. Ces interventions sont traditionnellement envisagées avec beaucoup d'hostilité par une grande partie de la doctrine, comme en témoigne la résolution adoptée en 1975 par l'Institut de Droit International ${ }^{105}$. Il convient toutefois de distinguer ici, pour les besoins de notre analyse, les guerres civiles (1) des guerres de sécession (2).

\section{L'intervention dans une guerre civile}

Si l'intervention dans une guerre civile semble être en principe contraire au droit positif (a), certaines exceptions pourraient éventuellement accompagner ce principe (b).

a) Le principe de non-intervention dans une guerre civile ou lors d'une insurrection

Une guerre civile est un " conflit armé non interétatique mettant aux prises soit un gouvernement établi avec un mouvement insurrectionnel, soit des groupes se disputant entre eux le pouvoir de l'État » ${ }^{106}$. Cette définition, qui distingue clairement une guerre civile d'une guerre de sécession (infra), montre pourquoi l'intervention sollicitée dans une telle guerre devrait en principe être considérée comme contraire au principe de non-intervention dans les affaires intérieures, tel que complété par le droit des peuples à disposer d'eux-mêmes. Nous avons vu, en effet, dans notre première partie, pourquoi ces principes interdisent à un État tiers d'arbitrer militairement une telle lutte pour le pouvoir au sein d'un autre État. Point n'est donc besoin ici de rappeler le vieux et obsolète

103. Pour certains cas, voy. J. SALMON, «Les circonstances excluant l'illicéité » in P. WEIL (dir.), Responsabilité internationale, Paris, Pedone, 1987, p. 97.

104. Tout au contraire, l'argument du consentement a joué un rôle prépondérant dans l'argumentation des deux parties. L'Ouganda a ainsi essayé de démontrer qu'un tel consentement de la RDC existait aussi pendant d'autres périodes critiques (chose que la RDC a refusée), tandis que la RDC a mis l'accent sur «l'accueil» de ces contingents ougandais pendant la période mai 1997-août 1998 pour soutenir qu'aucun défaut de vigilance ne doit lui être attribué pendant cette période par rapport aux activités des rebelles anti-ougandais (chose que l'Ouganda a refusée).

105. Le prudent avant-projet de résolution du rapporteur D. Schindler proposé en 1973 aux termes d'un rapport lui-même très nuancé et pragmatique, a finalement cédé sa place en 1975 , après plusieurs déchirements et des débats enflammés au sein de l'Institut, à une résolution monolithique, condamnant pratiquement toute intervention dans une guerre civile, adoptée par 16 voix pour, 6 contre et 16 abstentions. Comp. l'avant projet in Annuaire IDI, 1973, pp. 506-510 avec la résolution finale, intitulée " Le principe de non-intervention dans les guerres civiles » in Annuaire IDI, 1975, pp. 544-549.

106. J. SAlMON (dir.), Dictionnaire de droit international public, op. cit., p. 538. 


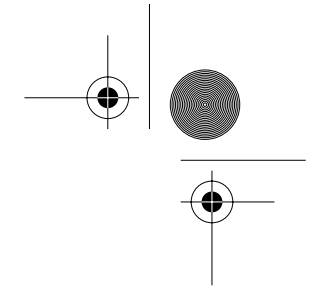

« droit de reconnaissance de belligérance » 107 , ni les «trois théories » contradictoires avancées traditionnellement par la doctrine ${ }^{108}$. Il nous semble en revanche beaucoup plus intéressant d'examiner la pratique des États pour constater que celle-ci confirme le principe de non-intervention en cas de guerre civile ou d'insurrection populaire même lorsque l'intervention est sollicitée par le gouvernement établi.

Il faut tout d'abord remarquer que les États qui interviennent militairement sur la base du consentement du pays hôte prennent généralement toutes les précautions pour montrer que leur action ne peut pas être assimilée à une intervention dans une guerre civile. Ainsi, les États qui interviennent essayent, soit de minimiser la finalité de leur intervention, en prétendant, par exemple, que leur seul but est de "protéger des nationaux" ou de "maintenir l'ordre » lors d'une simple "mutinerie", soit au contraire de maximaliser la raison de cette intervention en prétendant qu'ils aident l'État, à sa demande, à faire face à une "agression extérieure "109. Quelle que soit la réalité sur le terrain, le discours juridique des États intervenants est pratiquement toujours orienté vers d'autres justifications que l'intervention dans une guerre civile et ces États n'hésitent d'ailleurs pas parfois à laisser entendre qu'ils "n'ont pas à » intervenir dans une guerre civile au profit d'une des parties ${ }^{110}$. C'est cette même justification juridique qui est d'ailleurs aussi parfois avancée pour refuser de répondre favorablement à une demande d'intervention, en écartant, si nécessaire, des accords de défense ou de coopération militaire ${ }^{111}$ que l'État invitant souhaite

107. Pour lequel voy. par exemple J. VeRHOEVEN, La reconnaissance internationale dans la pratique contemporaine, Paris, Pedone, 1975, pp. 100 et ss. ou C. LE MON, « Unilateral Intervention by Invitation in Civils Wars : The Effective Control Tested ", N.Y.U.J.Int'L \& Pol., vol 35, 2003, pp. 746 et s.

108. Selon la première théorie, seule l'assistance au gouvernement établi est licite, celle aux rebelles étant illicite. Selon la deuxième, aucune assistance armée, qu'elle soit octroyée aux rebelles ou au gouvernement, n'est licite. La troisième théorie, qui contraste complètement avec le droit positif contemporain, prône que l'assistance à l'une ou à l'autre partie lors d'une guerre civile est également licite. Voy. R. KoLB, Ius contra bellum..., op. cit., pp. 226-228 ou le rapport précité de D. SCHINDLER in Annuaire IDI, 1973, pp. 428 et ss.

109. C'est ainsi, par exemple, que la France a essayé de justifier les deux raids aériens contre une colonne de véhicules du Polisario, au mois de mai 1978, en Mauritanie, en invoquant l'appel des autorités mauritaniennes et la protection des ressortissants français contre les activités du front qui avait, lors de raids antérieurs, pris en otage des ressortissants français. Le 7 mai 1978, le ministre français des affaires étrangères déclarait sur Europe I : «La Mauritanie est l'objet d'une agression qui est soutenue de l'extérieur, et elle a demandé notre aide pour appuyer les forces mauritaniennes lorsque celles-ci étaient prises sous le feu de colonnes rebelles notamment et dans les cas où ces colonnes menaçaient des ressortissants " (cité par C. PoURRE, Les interventions extérieures..., op. cit., p. 550).

110. Lors, par exemple, de l'opération de Stanleyville en 1964, la Belgique comme les États-Unis ont beaucoup insisté sur le fait que cette opération était strictement humanitaire (supra, note 83), et ne pouvait nullement être considérée comme une "intervention dans les affaires congolaises ou africaines " (S/PV 1173 du 11 déc. 1964). De manière similaire, lors de l'opération franco-belge au Shaba de 1978 (supra, notes 85-86), le ministre belge des affaires étrangères déclarait qu'« il ne s'agissait pas pour nous d'envoyer au Zaïre des troupes pour rétablir l'ordre, c'est-à-dire soutenir un gouvernement... " (cité par N. RONZITTI, Rescuing Nationals..., op. cit., p. 80).

111. Par exemple, les accords actuellement en vigueur entre la France et plusieurs pays africains ne prévoient pas une intervention de la France dans une guerre civile au profit du gouvernement central. Bien que l'hypothèse de l'existence de certaines "clauses secrètes » allant dans ce sens ait souvent été évoquée, le texte officiel des accords se réfère généralement à une aide destinée à repousser une agression ou une menace extérieures, précisant souvent par ailleurs, que « la défense intérieure est de la responsabilité nationale» de l'État et que les forces francaises stationnées sur certains de ces pays "ne peuvent en aucun cas être associées à la préparation et à l'exécution d'opérations de guerre, de maintien ou de rétablissement de l'ordre ou de la légalité ». La France a toujours souligné qu'en tout état de cause elle se réservait un pouvoir discrétionnaire en cas de demande pour la mise en œuvre d'une telle assistance militaire et qu'il n'y avait, en matière d'intervention, « ni un droit pour les Africains, ni un devoir pour la France ", car « aucun gouvernement africain ne peut obliger le gouvernement francais à engager ses hommes " (déclarations de Pierre Messmer dans Le Monde du $1^{\text {er }}$ octobre 1964). De fait, la France a parfois décliné les demandes de certains pays africains considérant qu'il s'agissait d'appels " pour maintenir un gouvernement au pouvoir» (C. POURRE, Les interventions extérieures..., op.cit., p. 485).
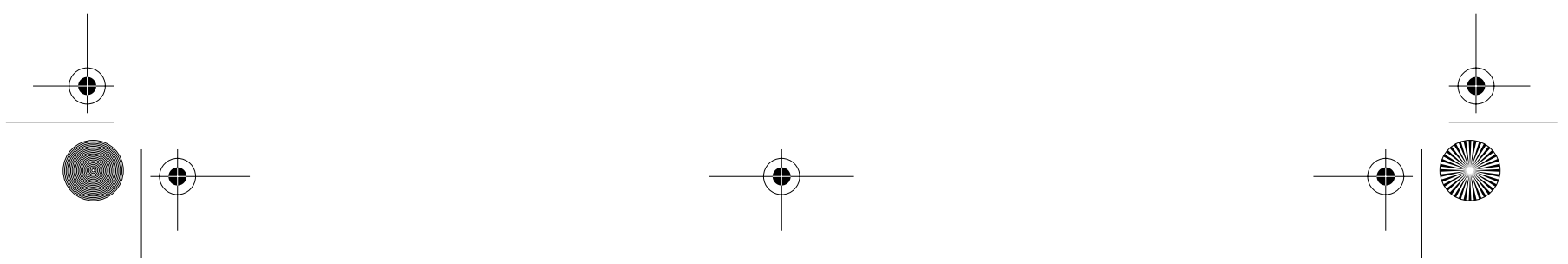
«actionner» 112 . Le discours de La Baule du président de la République française F. Mitterrand devant les chefs d'États et de gouvernements africain en juin 1990, résume très bien cet état d'esprit :

"Chaque fois qu'une menace extérieure poindra qui pourrait attenter à votre indépendance, la France sera présente à vos côtés. Elle l'a déjà démontré plusieurs fois et parfois dans des circonstances très difficiles. Mais notre rôle à nous, pays étranger, fut-il ami, n'est pas d'intervenir dans des conflits intérieurs. Dans ce cas-là, la France en accord avec les dirigeants, veillera à protéger ses concitoyens, ses ressortissants ; mais elle n'entend pas arbitrer les conflits » 113 .

Mais au-delà du discours juridique des États intervenants eux-mêmes (qui peut parfois bien sûr être en inadéquation avec leur comportement réel sur le terrain), les différentes réactions des États tiers lors de certaines interventions sollicitées dans des guerres civiles, constituent des témoignages supplémentaires de l'opinio juris des Etats dans ce domaine. Écartant les justifications « maximalistes » ou « minimalistes » des États intervenants considérées comme des prétextes, les États tiers (dont l'identité varie en fonction des crises) ont souvent critiqué les interventions sollicitées dans des guerres civiles comme contraires au droit des peuples de choisir leur gouvernement sans ingérence extérieure. De telles réactions se sont par exemple manifestées à la suite des interventions militaires de l'URSS en Hongrie en $1956^{114}$ et en Afghanistan en $1979^{115}$, des États-Unis en

112. Ainsi, par exemple, en septembre 2002, le gouvernement de la Côte d'Ivoire a déclaré avoir " actionné les accords de défense » qui le lient à la France, demandant à cette dernière de l'aider militairement à mater la rébellion du Nord (voy. "La Côte d'Ivoire "a actionné" ses accords de défense avec la France ", $S D A, 28$ septembre 2002). La France a pourtant décliné cette invitation et refusé de s'engager audelà d'une simple opération de sauvetage et de protection des ressortissants français et étrangers, estimant qu'il n'y avait pas «suffisamment de preuves d'une agression extérieure " voy. C. AYAD, "La France s'engage à reculons ", Libération, 30 septembre 2002) et qu'il n'était donc pas question de " s'embarquer dans une affaire purement interne », de « faire la police », ni de " jouer les arbitres » (voy. V. HUGEUX, «La France dans le bourbier ivoirien ", L'Express, 17 octobre 2002). À cet égard, le ministre français des affaires étrangères a déclaré au Sénat que, si sur un plan politique la France " apportait son soutien au gouvernement démocratiquement élu de la Côte d'Ivoire », la nature de l'intervention française était dictée par le «principe de non-immixtion dans les affaires intérieures de la Côte d'Ivoire». Le "souci de sécuriser nos compatriotes présents en Côte d'Ivoire ", continuait M. de Villepin, " conduisait la France à assumer ses responsabilités et non à prendre position» (in News Press, 7 octobre 2002). Plusieurs autres responsables politiques et militaires ont souligné que la doctrine de la France était «ni ingérence, ni indifférence » et que si la France voulait " empêcher un nouveau Rwanda ", elle ne voulait pas «s'impliquer dans les dispositifs militaires des mutins ou du gouvernement pour ne pas être taxée d'ingérence dans les affaires internes du pays ». Malgré cette neutralité officielle, la presse n'a pas manqué de souligner qu'« en empêchant [en septembre 2002] les rebelles du Nord, mieux armés, de marcher sur Abidjan, les militaires de l'opération "Licorne" ont sauvé le régime du président Gbagbo » (voy. Le Figaro du 25 septembre 2002 et du 4 février 2003).

113. Déclaration du président de la République française à l'occasion de la seizième conférence des chefs d'État de France et d'Afrique, La Baule, 19-21 juin 1990, DAI, nov. 1990.

114. Pour un résumé des débats au sein du Conseil de sécurité et de l'Assemblée générale où une majorité écrasante d'États a considéré que l'intervention soviétique visait à réprimer un mouvement populaire et constituait donc une violation flagrante du droit du peuple hongrois à l'autodétermination sans ingérence extérieure, voy. L. DoSWALD-BECK, "The Legal Validity... ", op. cit., pp. 222-226.

115. L'intervention en Afghanistan a été très sévèrement critiquée par plusieurs pays au sein du Conseil de sécurité et de l'Assemblée générale comme contraire au droit du peuple afghan de choisir son gouvernement sans ingérence extérieure (voy. par ex. S/PV 2186-2190 du 5-7 janvier 1980). Un projet de résolution (S/13729 du 6 janvier 1980) du Conseil qui condamnait cette intervention en soulignant «the résolution $(\mathrm{S} / 13729$ du 6 janvier 1980) du Conseil qui condamnait cette intervention en soulignant «the
right of all peoples to determine their own future free from outside interference, including their right to choose their own government " a recueilli 13 voix pour, mais n'a pu être adopté en raison du veto soviétique. L'Assemblée générale a néanmoins condamné cette intervention en réaffirmant « le droit du peuple afghan de décider lui-même de la forme de son gouvernement et de choisir son système économique, politique et social sans ingérence, subversion, coercition ou contrainte de l'extérieur sous quelque forme que ce soit » (A/RES 35/37, adoptée par 111 voix pour, 22 contre et 12 abstentions le 20 nov. 1980). La phrase a été reprise dans plusieurs autres résolutions similaires de l'Assemblée.

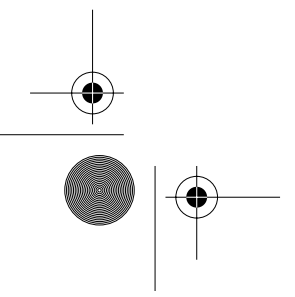


République dominicaine en $1965^{116}$ ou à la Grenade en $1983^{117}$, ou encore lors d'autres interventions conduites par des pays comme la Belgique 118 ou la France ${ }^{119}$. Et s'il est vrai que dans certains de ces cas l'existence même d'un consentement valide a été contestée, la teneur des déclarations des États tiers laisse peu de doutes quant au fait que leur position aurait été similaire si le consentement avait été considéré comme valide ${ }^{120}$.

\section{b) L'existence d'éventuelles exceptions au principe}

Si l'existence d'un principe de non-intervention dans une guerre civile (et $a$ fortiori lors d'une insurrection populaire) semble être confirmée par l'examen de la pratique des États, la question qui se pose est de savoir si des exceptions éventuelles accompagnent ce principe. Deux sortes de situations doivent ici retenir particulièrement notre attention.

(i) La première concerne l'éventuel droit pour un État d'accepter une invitation pour intervenir au profit d'un gouvernement qui se trouve confronté à une situation qui n'a pas encore pris les dimensions d'une guerre civile entendue comme un conflit armé interne. Cette distinction entre troubles internes et guerre civile est bien établie par l'article premier du protocole II de 1977 additionnel aux conventions de Genève relatif aux conflits armés non internationaux qui précise qu'il « ne s'applique pas aux situations de tensions internes, de troubles intérieurs, comme les émeutes, les actes isolés et sporadiques de violence et autres actes analogues, qui ne sont pas considérés comme des conflits armés ». Pourrait-on penser que dans de telles situations l'intervention au profit du gouvernement central est permise?

La réponse doit être prudente. Nous avons vu, en effet, que les principes pertinents en l'espèce (et surtout le droit à l'autodétermination) n'interdisent pas l'intervention dans une guerre civile per se (par exemple une intervention sollicitée pour sauver des nationaux dans une telle guerre reste en principe licite). Ils interdisent plutôt une finalité précise qui est d'arbitrer militairement, en faveur de l'une des parties, une lutte pour le pouvoir au sein d'un État. Or, une telle lutte peut exister en dehors de toute situation de conflit armé. Il semble

116. Pour un résumé de ces réactions voy. L. DoswALD-BECK, "The Legal Validity... ", op. cit., p. 229 .

117. L'intervention à la Grenade a été aussi considérée par plusieurs États au sein du Conseil de sécurité comme une violation du droit des peuples à choisir leur gouvernement sans ingérence extérieure (voy. S/PV.2487, 2489 et 2491 du 25-27 oct. 1983). L'Assemblée générale l'a condamnée en « réaffirmant le droit souverain et inaliénable de la Grenade de déterminer librement son propre régime politique [...] sans intervention, ingérence, subversion, coercition ou contrainte ni menace extérieures sous quelque forme que ce soit » (A/RES 38/7 du 2 nov. 1983, adoptée par 108-9-27)

118. Certains États, menés par l'URSS, ont pu ainsi voir dans l'éphémère intervention américanobelge au Congo de 1964 (supra, notes 83-84) une volonté d'intervenir dans une guerre civile en niant le droit du peuple congolais à l'autodétermination, voire une volonté d'établir une « tête de pont du colonialisme en Afrique centrale » (voy. A. GERARD, «L'opération Stanleyville-Paulis... », op. cit., pp. 249-250).

119. Certaines interventions françaises ont été critiquées par d'autres pays comme une « ingérence dans les affaires intérieures » des pays africains, voire comme des "guerres coloniales " (voy. par exemple certaines réactions suscitées lors de l'intervention au Gabon en 1964, les raids aériens contre le Polisario en 1978 ou de l'opération au Shaba la même année).

120. Voy. par ex. à propos des trois interventions soviétiques précitées les remarques de A. TANCA, Foreign Armed Intervention..., op. cit., pp. et 33 et 43 . Voy. aussi de manière plus générale la position de certains États lors des débats sur l'adoption de la résolution 2625 telle que résumée dans le rapport de la sixième commission: "On a fait observer qu'actuellement prévalait la théorie selon laquelle les États tiers ne doivent pas s'immiscer, du moins par des moyens militaires, dans les guerres civiles, quand bien même le gouvernement légitime du pays intéressé le leur demanderait " (voy. Nations Unies, Annuaire Juridique, 1968, pp. 130-131).
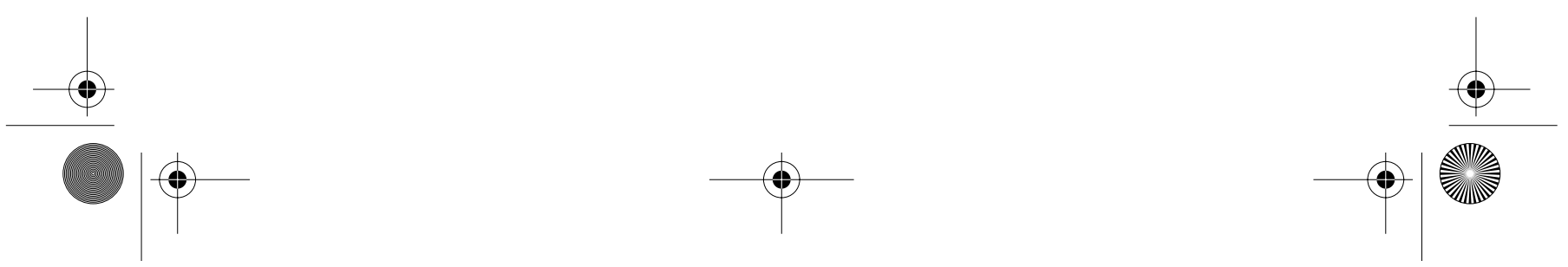
alors inconcevable de permettre à un État tiers d'intervenir pour aider un gouvernement central à mater un soulèvement populaire ${ }^{121}$ ou pour influencer le résultat d'une élection.

Ainsi, par exemple, il est symptomatique que la fin de la guerre civile au Liban n'a pas empêché le Conseil de sécurité de demander à plusieurs reprises, et avec une rigueur particulière dans le cas de la S/RES 1559 du 2 septembre 2004, le retrait de «toutes les forces étrangères qui y sont encore ". Cette résolution, qui visait les troupes syriennes, a été adoptée malgré la vive opposition du gouvernement libanais qui a souligné devant le Conseil de sécurité que «les forces syriennes sont venues au Liban à notre demande légitime » et qui, devant la détermination du Conseil, est allé jusqu'à déclarer que " jamais l'Organisation ne s'est ingérée d'une telle façon dans les affaires d'un État, quel qu'il soit » ${ }^{122}$. Les promoteurs de cette résolution ont néanmoins rétorqué que " le gouvernement syrien a imposé sa volonté politique au Liban et a forcé le Cabinet et l'Assemblée nationale libanaise à amender la Constitution et à interrompre le processus électoral en prorogeant le mandat du Président actuel de trois ans ". Ils ont souligné que, compte tenu de «l'ingérence syrienne dans la vie politique du pays, et plus particulièrement dans le processus électoral ", "le peuple libanais n'est toujours pas en mesure d'exercer les droits qui lui reviennent en tant que peuple libre de procéder à ces choix ». Et ils ont conclu que le Conseil "ne commet pas d'ingérence", en adoptant cette résolution, car "c'est, au contraire, en s'abstenant que le Conseil cautionnerait l'ingérence inadmissible d'un État dans les affaires intérieures d'un autre État souverain " ${ }^{123}$. La résolution précitée, adoptée par 9 voix pour et 6 abstentions, demande alors « que soient strictement respectées la souveraineté, l'intégrité territoriale, l'unité et l'indépendance politique du Liban, placé sous l'autorité exclusive du gouvernement libanais ", afin que les élections dans ce pays puissent se dérouler "conformément à des règles constitutionnelles libanaises élaborées en dehors de toute interférence ou influence étrangère ». La Syrie a retiré ses troupes en avril 2005.

Les choses se compliquent néanmoins dans l'hypothèse d'un coup d'État militaire destiné à renverser un gouvernement démocratiquement élu (qui ne peut pas non plus être automatiquement assimilé à une guerre civile). Il nous semble que la reconnaissance d'un droit d'intervenir militairement pour secourir un gouvernement renversé, dans un tel cas, supposerait l'abandon de la conception classique du droit à l'autodétermination «interne» (supra, I, C, 2), au profit d'un droit des peuples à un gouvernement démocratique. Or, un tel « droit à la démocratie " ne semble pas encore exister en dehors du cadre euro-américain et $a$ fortiori il ne semble donc pas exister de droit à l'intervention militaire pour restaurer le démocratie ${ }^{124}$. Il est significatif, à cet égard, que l'intervention militaire en Haïti pour la restauration du gouvernement Aristide en 1994, n'a pu être légitimée que par l'adoption de la résolution 940 du Conseil de sécurité, basée sur le chapitre VII de la Charte. Certes, nous n'ignorons ni les progrès

121. L'histoire très récente nous offre plusieurs exemples de tels soulèvements populaires qui ont abouti au renversement des gouvernements en place, comme la "révolution des roses " en Géorgie fin 2003, la " révolution orange " en Ukraine de novembre-décembre 2004 ou la "révolution des tulipes " au Kirghizistan en mars 2005 (voy. par ex. "En ex-URSS, "élection" rime désormais avec "révolution" ", Agence France Presse, 27 mars 2005 ou « La contagion révolutionnaire inquiète V. Poutine ", Le Temps, 19 avril 2005$)$.

122. S/PV 5028 du 2 sept. 2004, p. 3.

123. Déclarations des Etats-Unis et de la France, ibid.,pp. 4 et 5 . Voy. aussi les rapports du secrétaire général sur la question in S/2004/777 du $1^{\mathrm{er}}$ octobre 2004 et S/2005/272 du 26 avril 2005 ainsi que la "Déclaration franco-américaine sur le Liban » du $1^{\mathrm{er}}$ mars 2005 in DAI, 11 mars 2005. 124. Voy. T. CHRISTAKIS, Le droit à l'autodétermination... op. cit., pp. 323-506.
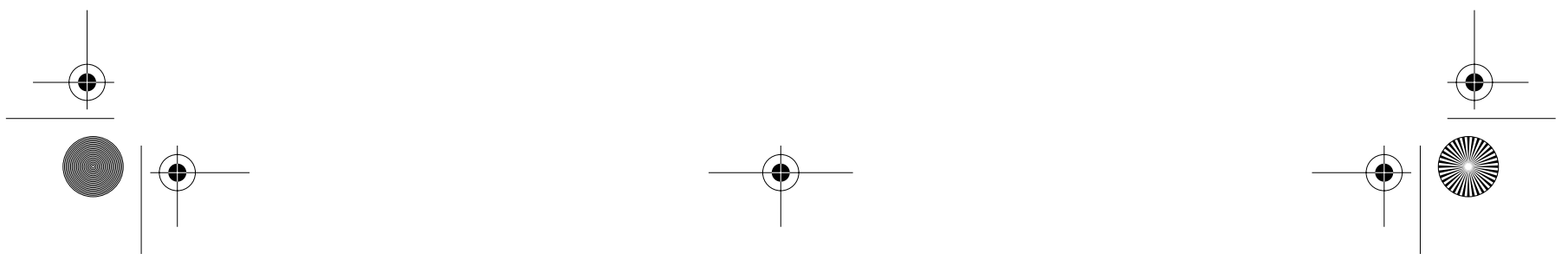
enregistrés en faveur de l'émergence d'un principe de légitimité démocratique sur le plan universel, ni certaines déclarations timides et contradictoires de certains responsables politiques au profit de "l'intervention démocratique » 125 . Mais en l'état actuel du droit, il est difficile de conclure que l'assistance licite à un gouvernement démocratique, qui peut prendre plusieurs formes, préventives ou curatives (par exemple des sanctions non militaires), puisse aller jusqu'à l'intervention militaire pour sa restauration ${ }^{126}$. En tout état de cause, l'émergence d'un tel droit devrait être accompagnée de plusieurs gardes-fous, car l'histoire est jalonnée d'abus et l'argument de la défense de la "démocratie » (très souvent plus fictive que réelle) pourrait devenir un formidable cheval de Troie pour permettre l'interventionnisme permanent des grandes puissances.

En revanche, l'intervention sollicitée pourrait éventuellement être moins difficilement admise si elle revêtait un caractère complètement neutre (ex. : protection de certaines installations dangereuses pendant une émeute) ou si elle intervenait dans le cadre d'une situation qui ne peut pas être automatiquement assimilée à une "lutte pour le pouvoir ", comme c'est par exemple le cas d'une simple mutinerie de soldats ${ }^{127}$.

(ii) La seconde question que l'on doit se poser concerne l'intervention sollicitée dans une guerre civile déjà internationalisée par une aide extérieure à l'insurrection. La pratique montre en effet que les États invoquent très souvent une aide extérieure apportée aux rebelles afin de prouver le bien fondé de leur décision de voler au secours du gouvernement central ${ }^{128}$. Il faut d'ailleurs

125. Ainsi, par exemple, le ministre français délégué à la coopération, Jacques Godfrain, déclarait en 1996 que : "La France interviendra chaque fois qu'un pouvoir démocratiquement élu sera destitué par un coup d'État, lorsqu'il existe des accords de coopération militaire». En réalité, cette déclaration, qui semblait plutôt viser la situation précise en République centrafricaine, était accompagnée de plusieurs autres déclarations selon lesquelles «il n'est pas question de jouer les gendarmes en Afrique ". Voy. Le Monde du 16 et du 22 mai 1996 ainsi que Le Point du 25 mai 1996.

126. Contra G. NolTE, Eingreifen..., op.cit., p. 637 ou D. WIPPMAN, «Pro-Democratic Intervention by Invitation " in G. Fox, B. RoTH, Democratic governance and international law, Cambridge Univ. Press, 2000, pp. 293-327. L'argument de l'intervention de la CEDEAO en Sierra Leone en 1998, souvent invoqué par les partisans de l'« intervention pro-démocratique ", ne nous semble pas décisif pour plusieurs raisons, y compris le fait que l'ECOMOG elle-même n'a pas invoqué l'invitation du président Kabbah pour justifier son intervention militaire, mais plutôt le «droit de légitime défense " face aux attaques de la force de la junte contre les contingents de la force régionale de maintien de la paix (voy. S/1998/123 du 13 février 1998). Dans tous les cas on voit mal comment cette initiative militaire d'une des dictatures les plus sanguinaires d'Afrique, celle du dictateur nigérian S. Abacha (qui présidait la CEDEAO), pourrait être considérée comme donnant naissance à un droit universel d'intervention pro-démocratique.

127. On peut ainsi remarquer que l'aide apportée, en janvier 1964, par le Royaume-Uni, au Tanganyka, au Kenya et à l'Ouganda pour mater, à la demande des gouvernements concernés, la mutinerie de certains officiers qui réclamaient « l'augmentation des soldes, l'accélération de l'avancement et l'africanisation des cadres ", n'a pas connu de réactions négatives. Il en va de même avec l'intervention de la France en République centrafricaine en avril et mai 1996 qui a permis de mater deux mutineries (ayant pour objet respectivement le paiement des soldes et la décision du gouvernement de les désarmer). Lors de son intervention sollicitée au Gabon, en février 1964, le gouvernement français a tenté de minimiser les événements et de les qualifier de simple «mutinerie» diligentée par «des militaires uniquement soucieux de passer dans les grades supérieurs sans avoir accompli le temps voulu ». Plusieurs États ont néanmoins considéré qu'il s'agissait d'un simple prétexte pour sauver le gouvernement en place et ont dénoncé ce qu'ils ont qualifié d'« ingérence dans les affaires intérieures " (voy. M. BENNOUNA, Le consentement..., op. cit., pp. 42-45)

128. Il est difficile de recenser ici tous les cas d'intervention prétendument ou réellement sollicitée où l'argument d'une telle aide extérieure a été avancé comme justification principale ou exclusive par l'État intervenant, tellement ces cas sont nombreux. À titre d'exemple, on peut rappeler que l'argument a été avancé tantôt légitimement, tantôt de manière plus ou moins abusive, par le Royaume-uni lors de son intervention en Grèce (1944-1946), à Mascate \& Oman (1957) ou en Jordanie (1958), les États-Unis lors de l'intervention au Liban en 1958, l'URSS lors de ses interventions en Hongrie (1956) et en Afghanistan (1979), la France lors de ses interventions au Zaïre (1978), au Tchad (1978, 1983 et 1986), au Togo (1986), à Djibouti (1991) et aux Comores (1995), le Maroc lors de l'opération au Zaïre (1977), ainsi que lors des interventions de Cuba en Angola (1975), du Sénégal en Gambie (1981), et du Zimbabwe et de la Tanzanie au Mozambique (1986).
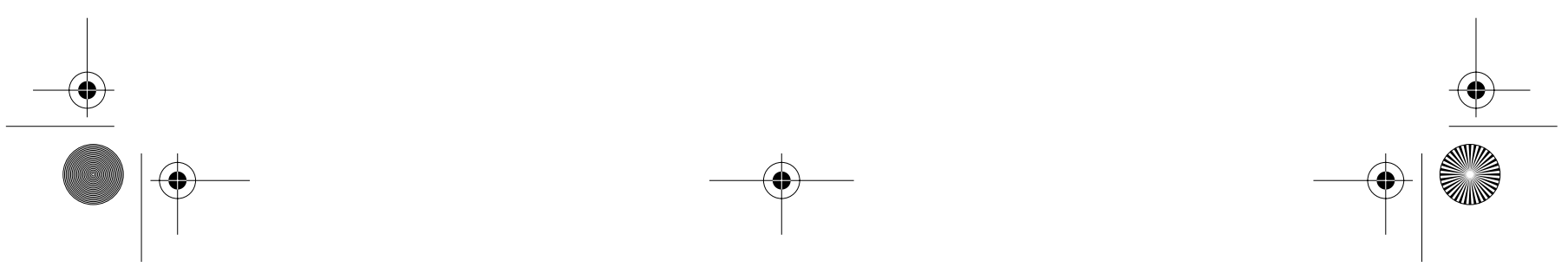
observer que les arguments avancés vont souvent au-delà de l'hypothèse classique d'une agression armée directe ouvrant droit à une légitime défense collective. Les États font ainsi souvent appel à la notion d'agression indirecte, voire au concept de "menace extérieure » ou de "subversion extérieure » pour revendiquer un droit général de "contre-intervention " au profit du gouvernement chaque fois qu'une puissance étrangère a violé le principe de non-intervention au profit des rebelles. $\mathrm{Si}$, dans de rares cas, ces contre-interventions n'ont soulevé aucune protestation au sein de la communauté internationale ${ }^{129}$, les réactions qu'elles ont suscitées dans les autres cas ne visaient pas à remettre en cause le principe de contre-intervention, mais invoquaient plutôt l'argument, fondé ou non selon le cas, de l'inexistence d'une intervention initiale extérieure au profit des rebelles ${ }^{130}$. Le principe de la licéité d'une intervention sollicitée déclenchée dans de telles circonstances a d'ailleurs été affirmé par plusieurs États in tempore non suspecto, en dehors de toute crise ${ }^{131}$.

Si l'on peut donc conclure qu'en principe une telle intervention devrait être permise, il faut aussi souligner que cette conclusion est subordonnée au respect d'au moins trois limites importantes. Premièrement, pour pouvoir justifier une intervention militaire au profit du gouvernement établi, le soutien que les rebelles reçoivent de l'étranger doit être «substantiel » ${ }^{132}$, même s'il n'est pas nécessaire qu'il atteigne les dimensions d'une agression armée. Deuxièmement, le but de l'intervention sollicitée ne devrait, logiquement, être que d'éliminer cette subversion extérieure et ses conséquences: si l'intervention extérieure au profit des rebelles cesse, la raison qui légitimait l'intervention au profit $\mathrm{du}$ gouvernement central cesse aussi. Enfin, si l'intervention extérieure en faveur des rebelles n'a pas pris la dimension d'une agression armée, le consentement à l'intervention ne peut alors certainement pas autoriser l'intervenant (ou l'invitant) à attaquer le territoire de l'État responsable des actes de subversion.

\section{L'intervention sollicitée pour lutter contre un groupe sécessionniste armé}

Bien que parfois l'amalgame soit fait entre guerre civile et guerre de sécession ${ }^{133}$, il est clair que les deux notions doivent être distinguées. Une guerre

129. C'est le cas, par exemple, de l'intervention de la France aux Comores en 1995, présentée comme une réponse à "l'agression extérieure menée par un commando de mercenaires " (Déclaration du ministre des affaires étrangères de la France devant l'Assemblée nationale, citée in Politique étrangère, octobre 1995, p. 147).

130. C'est ainsi, par exemple, que la République Arabe Unie a nié en 1958 toute participation de son pays dans la "question intérieure libanaise", reprochant au Liban et aux États-Unis d'avoir "imaginé " cette participation afin "de donner un aspect international à un problème purement interne» (voy. M. BENNOUNA, Le consentement..., op. cit., p. 150).

131. Voy. par exemple la position claire du Royaume-Uni au sein de l'Assemblée générale lors des négociations pour l'élaboration de la résolution 2625 : "In the event that a State becomes a victim of unlawful intervention practised or supported by the Government of another State, it has the right to request aid and assistance from third States, which are correspondingly entitled to grant the aid and assistance required. Such aid and assistance may, if the unlawful intervention has taken the form of subversive activities leading to civil strife in which the dissident elements are receiving external support and encouragement, include armed assistance for the purpose of restoring normal conditions " (cité par L. DoSWALD-BECK, "The Legal Validity...", op. cit., p. 210). Voy. aussi par ex. supra, note 114.

132. Cf. D. SCHINDLER, «Le principe de non-intervention dans les guerres civiles ", Annuaire IDI, 1973 , p. 458.

133. Voy. par exemple la confusion entre les deux notions qui figure dans l'article 1 de la résolution sur « Le principe de non-intervention dans les guerres civiles " adoptée par l'Institut de droit international le 14 août 1975 (in Annuaire IDI, 1975, p. 546).
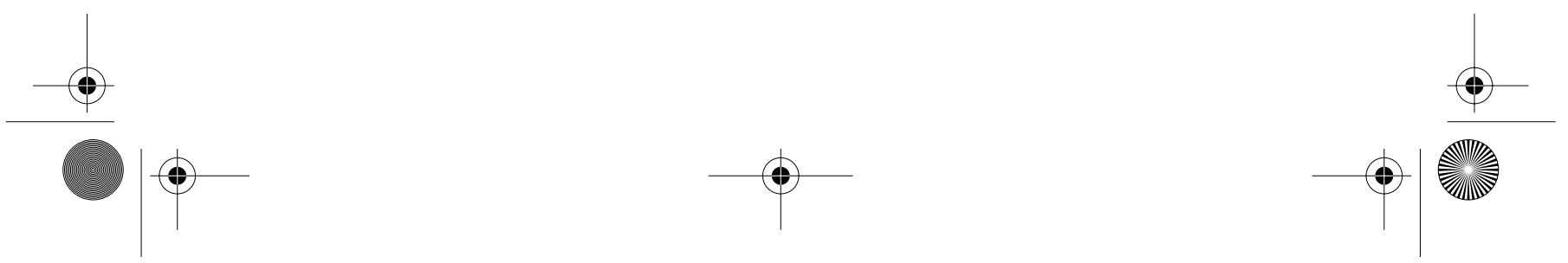
civile est une compétition pour le pouvoir à l'intérieur d'un État lors de laquelle un "mouvement insurrectionnel veut prendre le pouvoir du gouvernement en place $" 134$. Une guerre de sécession est un « [c] onflit armé non international dans lequel une fraction de la population d'un État lutte pour créer un nouvel État sur une partie du territoire de l'État d'origine ou pour rattacher cette partie de territoire à un État tiers " ${ }^{135}$. Dans la guerre de sécession, le mouvement sécessionniste lutte pour "créer un nouvel État", il ne s'agit pas d'une compétition pour le pouvoir central mais d'une tentative de mutiler l'État afin de créer, sur la partie amputée, un nouvel État indépendant. La distinction est donc très claire et elle a des conséquences importantes sur le plan juridique.

Ces conséquences sont surtout dues au fait que le principe de l'autodétermination ne prévoit, en dehors des situations de décolonisation ou d'occupation militaire, aucun droit d'un "peuple " ou d'une "minorité » quelconque à se constituer en État indépendant. Il ne semble donc exister aucune contrariété avec les principes analysés dans la première partie de cet article en cas d'intervention sollicitée pour porter assistance à un Etat en proie à un mouvement sécessionniste armé. Il est bien connu, en effet, que le renvoi que le droit international fait dans ce domaine au principe de l'effectivité est souvent interprété par les mouvements sécessionnistes et les gouvernements centraux comme un appel aux armes. Comme il a été remarqué : "military success is not just the only path to independence but it may also be the only way for a parent state to maintain its territorial integrity» ${ }^{136}$. Mais ceci ne signifie pas pour autant que le droit international renvoie dos-à-dos l'État et le groupe sécessionniste. Le droit demeure hostile à la sécession, il la réprouve faute de l'interdire, et érige contre elle des obstacles importants que l'effectivité peut sans doute surmonter, mais cela ne sera pas automatique et ne se fera pas sans peine ${ }^{137}$. Parmi ces obstacles, on compte précisément l'interdiction de toute aide extérieure aux sécessionnistes qui contraste avec l'aide dont peut bénéficier le gouvernement central aussi longtemps, bien sûr, que la sécession n'a pas abouti à la création d'un nouvel État indépendant.

Si cette aide, pour des raisons politiques évidentes, prend rarement la forme d'une intervention militaire directe, l'histoire nous offre tout de même quelques exemples d'intervention au profit et à la demande du gouvernement central. L'exemple le plus célèbre concerne sans doute les opérations militaires engagées par les Nations Unies au Congo contre les groupes sécessionnistes du Katanga en $1961^{138}$, mais on pourrait aussi citer d'autres cas, comme l'intervention de l'Inde à la demande du gouvernement du Sri Lanka en 1987, contre les Tigres de la libération du Tamil Eelam, intervention qui n'a pas provoqué de réactions au sein

134. J. SAlmon (dir.), Dictionnaire de droit international public, op. cit., p. 538.

135. Id., p. 539

136. L. FRANKEL, "International Law of Secession : New Rules for a New Era ", Houston J.I.L., vol. 14, 1992, p. 539

137. Pour toutes ces questions, voy. T. CHRISTAKIS, Le droit à l'autodétermination ..., op. cit., pp. 35322 .

138. Si le secrétaire général de l'ONU, U. Thant, avait initialement déclaré qu'il avait « été obligé d'opposer une fin de non-recevoir» à la demande d'intervention contre les sécessionnistes formulée par M. Lumumba, considérée comme "incompatible avec le statut et les fonctions de la Force ", il a accepté plus tard que l'activité de la Force des Nations Unies a "beaucoup contribué à donner effectivement poids à l'opposition de l'ONU à la sécession » et que «l'ONU a évité toute intervention si ce n'est pour s'opposer à la sécession en général ». Son représentant à Elisabethville, M. O’Brien, a déclaré, quant à lui, que "les Nations Unies ont obéi à la requête [du gouvernement central] " pour arrêter les leaders katangais et détruire le régime sécessionniste. Voy. J. SALMON, La reconnaissance d'État, Paris, A. Colin, 1971, pp. 127 et ss. et O'BrIEn, To Katanga and Back : A United Nations Case History, London, 1962 , pp. 241 et ss
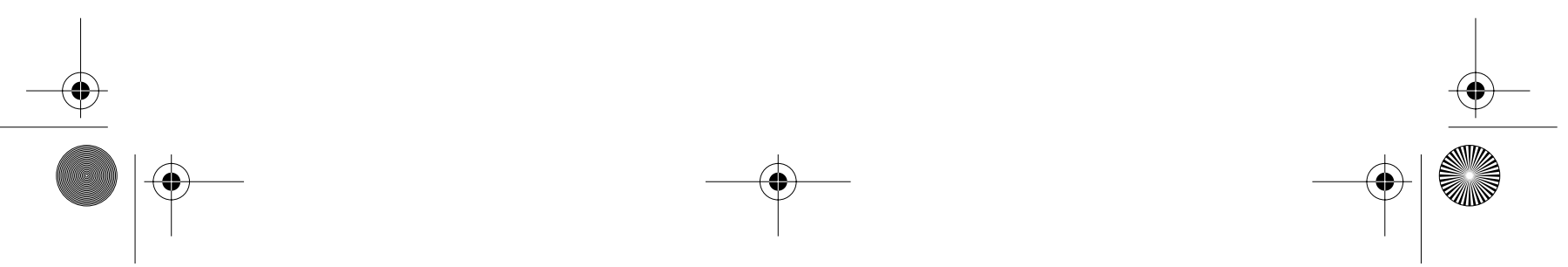
de la communauté internationale ${ }^{139}$, ou encore, mais dans une moindre mesure, l'intervention de la force multinationale contre les Serbes de Bosnie en août $1995^{140}$

\section{Situations où l'intervention est contraire au droit positif}

Sans prétendre dresser ici une liste exhaustive de ces situations, nous nous contenterons de présenter brièvement les plus importantes qui découlent souvent des analyses qui précèdent.

\section{Intervention sollicitée par les rebelles}

Nous avons vu, tout au long de cet article, que toute intervention militaire au profit des rebelles dans un conflit interne, en cours ou en gestation, sécessionniste ou non, est clairement prohibée par le droit international ${ }^{141}$. Les conclusions auxquelles la CIJ est parvenue en 1986 restent donc entièrement pertinentes.

\section{Intervention se retournant contre la souveraineté ou la volonté de l'État «invitant»}

$\mathrm{Si}$, dans la première partie de cet article, nous avons exclu l'intervention sollicitée du champ d'application du principe du non-recours à la force, nous avons expressément réservé l'hypothèse d'une intervention qui se retourne, d'une façon ou d'une autre, contre la souveraineté ou la volonté de l'État «invitant». Plusieurs situations spécifiques entrent dans cette catégorie.

En premier lieu, toute autorisation, exprimée par voie conventionnelle ou unilatérale, qui vise à rendre inopérant l'article $2, \S 4$ de la Charte ou à supprimer la règle relative à la prohibition de l'agression dans les relations internationales, est nulle et l'intervention déployée sur la base d'une telle "sollicitation » est illicite. L'histoire montre en effet que "les accords d'intervention" sont le plus souvent conclus sous la contrainte et, par conséquent, les règles codifiées par les articles 51 et 52 de la convention de Vienne suffisent à établir leur nullité absolue. Mais même si cette contrainte n'est pas prouvée, une disposition conventionnelle par laquelle un État octroie à un autre un droit d'intervention unilatérale contre lui est, par définition, contraire au jus cogens et nulle sur la base de l'article 53 ou 64 de cette même convention ${ }^{142}$. Les clauses de ce genre ont d'ailleurs pratiquement disparu des traités contemporains.

139. Pour une analyse, voy. C. LE MoN, «Unilateral Intervention... », op. cit., pp. 782 et ss. À l'instar de cet auteur, il est intéressant de souligner que quand, fin 1987, la Turquie a essayé de compare son intervention à Chypre avec l'intervention de l'Inde, tant le Sri Lanka que l'Inde ont vivement réagi, en écartant toute comparaison similaire compte tenu du fait qu'il s'agissait en l'espèce d'une intervention « à la demande spécifique du gouvernement de Sri Lanka et donc en pleine conformité avec le droit international ».

140. Cf. T. Christakis, L'ONU, le Chapitre VII et la crise Yougoslave, Paris, Montchrestien, 1996, p. 185.

141. Même les mouvements de libération nationale, dans le cadre de la décolonisation, n'ont pas pu vraiment bénéficier d'un tel droit d'intervention militaire directe à leur profit. Voy. A. CASSESE, SelfDetermination of Peoples, Cambridge Univ. Press, 1995, pp. 150-158.

142. On peut citer par exemple l'article 6 du traité d'amitié conclu en 1921 entre la Perse et la Russie fédérative, dénoncé unilatéralement par l'Iran (voy. M. REISMAN, « Termination of the USSR's Treaty Right of Intervention in Iran ", AJIL, vol. 74, 1980, pp. 144-154). On peut citer aussi l'effort désespéré du Sénat américain d'interpréter la Panama Canal Treaty de 1977 comme accordant aux États-Unis un droit de recourir unilatéralement à la force au Panama " si le canal est fermé ou si son fonctionnement

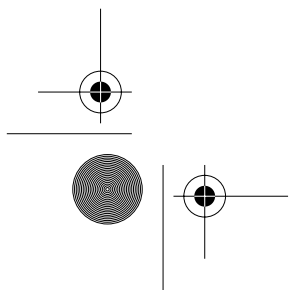


Certes, on peut imaginer une variante plus "souple " à ce genre de traités, où l'objet ne serait pas de permettre à un État A d'intervenir militairement contre un État B, mais plutôt de reconnaître au profit de l'État A le droit de décider d'une intervention unilatérale pour sauver des nationaux en danger, lutter contre des terroristes ou réaliser, sur le territoire de l'État B, l'un quelconque des objectifs licites d'une intervention sollicitée que nous avons déjà mentionnés. Ces traités ne sont pas bien sûr, en principe, contraires au jus cogens, mais ils ne dispensent pas non plus l'État qui souhaite intervenir de l'obligation d'obtenir le consentement de l'État «invitant» au moment même de l'intervention. Les traités en question ne peuvent, en effet, que créer un cadre de coopération militaire, une alliance, voire une présomption de consentement à l'intervention. Mais ils ne peuvent créer aucune obligation de subir une intervention militaire. Le refus clair de l'intervention de la part de l'État qui avait octroyé par voie conventionnelle la faculté d'intervention à un autre État a pour effet de rendre cette intervention contraire à l'article 2, § 4 de la Charte et au principe de non-intervention dans les affaires intérieures.

Les mêmes observations s'appliquent mutatis mutandis si l'invitation à l'intervention est donnée unilatéralement, en dehors de tout cadre conventionnel ${ }^{143}$. La révocation claire du consentement dans une telle hypothèse doit être respectée par l'État intervenant et toute prolongation de l'intervention au-delà de la terminaison du consentement devrait être considérée comme illicite, conformément à la logique consacrée par l'article 3 , alinéa (e) de la résolution 3314 (1974) sur la définition de l'agression.

\section{Interventions dépassant les limites autorisées par l'invitation ou par le droit international}

Nous avons constaté, tout au long de cet article, l'inadéquation qui existe souvent entre le discours juridique des États et leur comportement réel sur le

Suite de la note 142

est entravé » (amendement dit de Deconcini). Les États-Unis ont à peine osé invoquer l'article 4 de ce traité, tel qu'interprété par leur Sénat, pour justifier leur intervention au Panama en 1989, tant il était clair que non seulement les conditions posées par l' "amendement Deconcini " n'étaient pas réunies, mais que c'était au contraire leur intervention qui avait conduit à la première fermeture du canal en soixante-quinze ans d'existence. Encore plus tragique est le cas de l'article IV du «traité de garantie » du 16 août 1960 relatif à la création de l'État de Chypre, conclu entre le Royaume-Uni, la Grèce et la Turquie d'une part et les autorités chypriotes de l'autre. Imposé à la jeune république de Chypre comme le prix à payer pour son indépendance, cet article prévoyait en termes vagues qu'en cas de violation des dispositions de ce traité, les trois puissances garantes s'engagaient à se concerter pour trouver une solution commune, mais si cela s'avérait impossible « chacune des trois Puissances garantes se réserv[ait] le droit d'agir dans le but exclusif du rétablissement de l'ordre créé par le présent traité ». La République de Chypre a, à plusieurs reprises, au sein et en dehors de l'ONU, souligné que l'« action » des puissances garantes dont il est question dans cet article ne saurait être que pacifique et que toute autre interprétation aurait été contraire aux principes fondamentaux de la Charte et aux règles de jus cogens, ainsi bien sûr qu'à la souveraineté et à l'indépendance chypriotes. Ni le soutien de cette position par plusieurs autres États, ni le rappel formel par le Conseil de sécurité des obligations des États en vertu de l'article 2, § 4, cité in extenso dans certaines de ses résolutions sur Chypre (par ex. S/RES 186 du 4 mars 1964), ni les rappels de l'Assemblée générale de l'ONU au fait que «la République de Chypre [...] a le droit de jouir, conformément à la Charte des Nations Unies, et devrait jouir de la pleine souveraineté et d'une indépendance complète, sans intervention ni ingérence étrangères " (A/RES 2077 du 18 décembre 1965), n'ont empêché la Turquie d'invoquer en 1974 comme prétexte l'article IV du traité afin de provoquer la partition de facto de l'île en violation flagrante tant du droit international que de l'article IV lui même (qui reconnaissait comme «but exclusif " d'une "action " des puissances le "rétablissement de l'ordre créé par le traité »).

143. On pourrait certes soutenir que l'acte unilatéral d'invitation et son acceptation par l'État intervenant forment un accord non formalisé ou solo consensu. Mais l'on préfère mettre l'accent sur la caractère strictement unilatéral de l'invitation et de sa révocation.
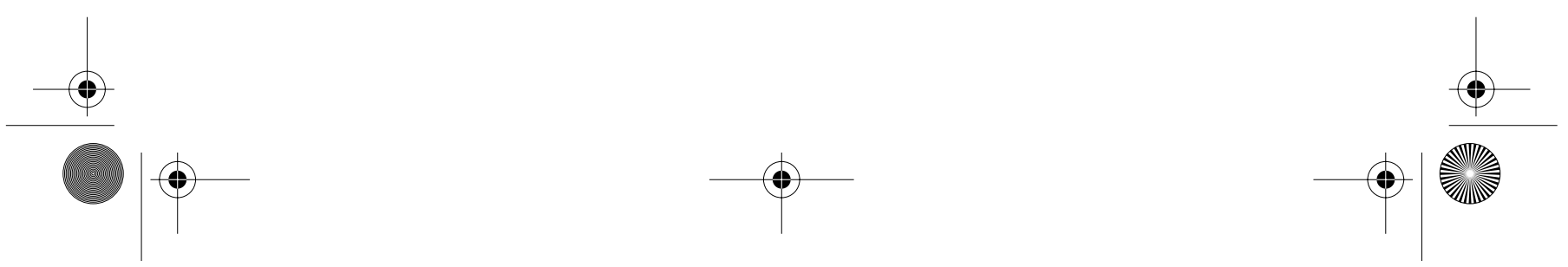
terrain. S'il va bien sans dire, il va encore mieux en soulignant que les interventions doivent toujours respecter à la fois le cadre strict de l'invitation et les limites fixées par le droit international. Un État ne peut pas ainsi invoquer, à l'appui d'une intervention sollicitée, une finalité considérée comme licite (par exemple le sauvetage des nationaux) pour viser en réalité un but illicite (telle la répression d'une insurrection populaire contre le gouvernement établi).

\section{Interventions fondées sur des invitations irrégulières}

Il va de soi que l'intervention doit se fonder sur une invitation « régulière ». Ceci signifie, tout d'abord, que le consentement ne doit pas être le produit d'une contrainte ou d'un autre vice du consentement : les articles 46 et suivants de la convention de Vienne sur le droit des traités s'appliquent ici mutatis mutandis. Le consentement doit d'ailleurs être donné avant l'intervention et non ex post facto : l'histoire nous offre, en effet, plusieurs exemples de pays qui ont essayé de justifier une intervention par le consentement d'un gouvernement qui n'a pu accéder au pouvoir que grâce à cette intervention ${ }^{144}$ ! Last, but not least, le consentement ne peut être donné que par un organe «dont la volonté est considérée, sur le plan international, comme étant la volonté de l'État » ${ }^{145}$. La question de savoir qui peut représenter l'État a fait couler beaucoup d'encre dans la doctrine et des débats enflammés ont entouré les critères de l'effectivité et/ou de la légitimité (y compris démocratique) des pouvoirs en place. Il s'agit d'un problème important, qui dépasse largement le cadre de notre article. Faute de pouvoir le traiter de manière exhaustive, il suffit de faire ici brièvement deux remarques. Premièrement, il semble découler de la pratique, que, quelles que soient les percées de la notion de "légitimité démocratique ", l'existence d'un gouvernement effectif reste le critère déterminant pour l'acceptation du caractère licite d'une intervention sollicitée ${ }^{146}$. Deuxièmement, le débat doctrinal a surtout été développé en liaison avec la question de la licéité de l'intervention dans une guerre civile au profit du gouvernement préexistant et c'est dans ce cadre que divers auteurs ont essayé de proposer les « doses » d'effectivité ou de légitimité que ce gouvernement devrait posséder pour lancer une invitation valide. Or, ce débat perd une grande partie de sa pertinence si l'on considère, comme nous l'avons fait, que l'intervention dans une lutte interne pour la conquête du pouvoir, est de toute façon contraire au droit international.

144. Voy. N. RonZITTI, «Use of Force, Jus Cogens and State Consent », op. cit., pp. 160 et ss. Cette observation est sans préjudice de la question de savoir si un consentement post facto valide peut être considéré comme une "renonciation » au sens de l'article 45 du projet de la CDI sur la responsabilité.

145. Selon R. Ago in Huitième rapport sur la responsabilité des États...., op. cit., § 70, p. 37.

146. Parmi les études les plus récentes voy. C. LE MON, «Unilateral Intervention by Invitation in Civils Wars : The Effective Control Tested », N.Y.U.J.Int'L \& Pol., vol. 35, 2003, pp. 741-793.
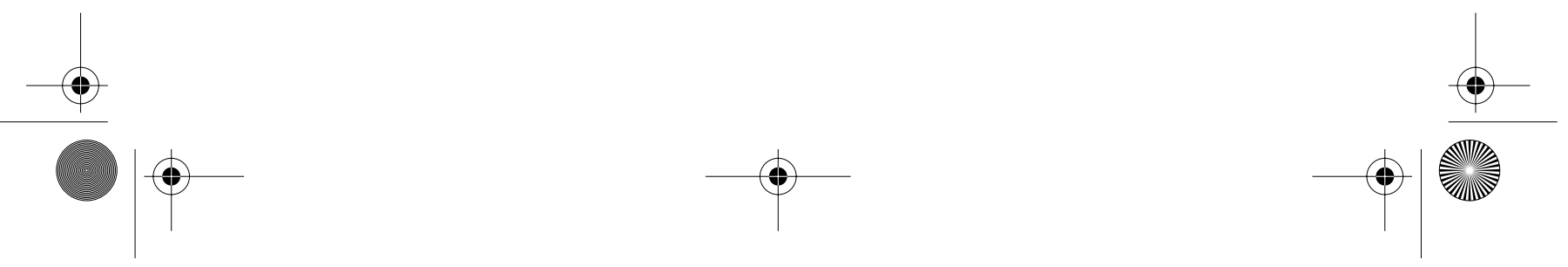